\title{
Interaction of the tick immune system with transmitted pathogens
}

\section{Ondřej Hajdušek ${ }^{1}$, Radek Šíma ${ }^{1}$, Nieves Ayllón ${ }^{2}$, Marie Jalovecká $^{3,4}$, Jan Perner ${ }^{3}$, José de la Fuente ${ }^{2,5}$ and Petr Kopáček ${ }^{1 *}$}

' Biological Centre ASCR, Institute of Parasitology, České Budějovice, Czech Republic

2 SaBio. Instituto de Investigación en Recursos Cinegéticos IREC-CSIC-UCLM-JCCM, Ciudad Real, Spain

${ }^{3}$ Faculty of Sciences, University of South Bohemia, České Budějovice, Czech Republic

4 UMR INRA ONIRIS 1300 BioEpAR, Nantes, France

${ }^{5}$ Department of Veterinary Pathobiology, Center for Veterinary Health Sciences, Oklahoma State University, Stillwater, OK, USA

Edited by:

Agustín Estrada-Peña, University of

Zaragoza, Spain

\section{Reviewed by:}

Xin Li, The Ohio State University, USA

Agustín Estrada-Peña, University of Zaragoza, Spain

\section{*Correspondence:}

Petr Kopáček, Institute of Parasitology, Biology Centre,

Academy of Sciences of the Czech Republic, Branišovská 31, 37005

České Budějovice, Czech Republic e-mail: kopajz@paru.cas.cz
Ticks are hematophagous arachnids transmitting a wide variety of pathogens including viruses, bacteria, and protozoans to their vertebrate hosts. The tick vector competence has to be intimately linked to the ability of transmitted pathogens to evade tick defense mechanisms encountered on their route through the tick body comprising midgut, hemolymph, salivary glands or ovaries. Tick innate immunity is, like in other invertebrates, based on an orchestrated action of humoral and cellular immune responses. The direct antimicrobial defense in ticks is accomplished by a variety of small molecules such as defensins, lysozymes or by tick-specific antimicrobial compounds such as microplusin/hebraein or 5.3-kDa family proteins. Phagocytosis of the invading microbes by tick hemocytes is likely mediated by the primordial complement-like system composed of thioester-containing proteins, fibrinogen-related lectins and convertase-like factors. Moreover, an important role in survival of the ingested microbes seems to be played by host proteins and redox balance maintenance in the tick midgut. Here, we summarize recent knowledge about the major components of tick immune system and focus on their interaction with the relevant tick-transmitted pathogens, represented by spirochetes (Borrelia), rickettsiae (Anaplasma), and protozoans (Babesia). Availability of the tick genomic database and feasibility of functional genomics based on RNA interference greatly contribute to the understanding of molecular and cellular interplay at the tick-pathogen interface and may provide new targets for blocking the transmission of tick pathogens.

Keywords: tick, tick-borne diseases, innate immunity, phagocytosis, antimicrobial peptides, Borrelia, Anaplasma, Babesia

\section{TICK-PATHOGEN INTERFACE: GENERAL CONSIDERATIONS}

Ticks are the most versatile arthropod diseases vectors capable to transmit the broadest spectrum of pathogens comprising viruses, bacteria, protozoa, fungi and nematodes to their vertebrate hosts (Jongejan and Uilenberg, 2004). The tick-borne diseases, such as Lyme disease, tick-borne encephalitis, rickettsiosis (spotted fever), ehrlichiosis or human granulocytic anaplasmosis, are of great concern in human health and their serious threat discourage people from outdoor work or leisure activities. No less important are tick-transmitted zoonoses, such as anaplasmosis, babesiosis, theileriosis and African swine fever that cause substantial economic losses to the livestock production worldwide.

The success rate of pathogens transmitted by ticks is mainly given by the favorable aspects of tick physiology arising from their adaptation to the relatively long-lasting blood feeding. The modulation of host immune and inflammatory responses by various bioactive molecules present in the tick saliva (Francischetti et al., 2009) facilitates pathogen acquisition and transmission.
Furthermore, the long-term persistence of ingested microbes in the midgut lumen is facilitated by the absence of extracellular digestive enzymatic apparatus, which is in ticks located inside the digestive vesicles of midgut cells (Sonenshine, 1991; Sojka et al., 2013). Nevertheless, ticks possess defense mechanisms that allow them to maintain the pathogens and commensal microbes at the level, which does not impair their fitness and further development. The long lasting co-evolution of ticks with pathogens resulted in the mutual tolerance, apparently adapted to the tick physiological differences (Mans, 2011). Therefore, the detailed knowledge of tick physiology and behavior is crucial to understand the fate of pathogens within the tick vector. For instance, the length of feeding, that strikingly differs between the hard and soft ticks (days vs. minutes, respectively), definitely shape the course of pathogen transmission. Pathogens transmitted by the hard ticks (Ixodidae) usually undergo several days of development until they infect the host. On the contrary, pathogens transmitted by the soft ticks (Argasidae) are ready for transmission immediately after the feeding starts. A good example here 
is difference in the time of transmission between the Borrelia spirochetes causing Lyme disease (transmission several days after attachment) and relapsing fever (transmission several minutes after attachment) vectored by the hard and soft ticks, respectively (Sonenshine, 1991). Another important aspect that should be taken into consideration is the tick feeding strategy, the differences between one- and multi-host ticks in terms of transovarial and transstadial transmission.

The transmitting pathogen acquired from the infected host has to overcome several tissue barriers within the tick body comprising midgut, hemocoel and salivary glands or ovary (in case of transovarial transmission). Each of these compartments may play a decisive role in the tick vector competence for a certain microbe. The tick midgut is probably the most important tissue for survival and proliferation of the pathogens since many of them have to persist here until the molting and subsequent feeding. On their route from the midgut to the peripheral tissues, the pathogens are facing cellular and humoral defense mechanisms functioning within the tick hemolymph. Therefore, the abilities to cope with or avoid the tick immune responses are crucial for the pathogen transmission. During the last two decades, our knowledge about the invertebrate immunity has rapidly expanded, mainly given by the research on the model organisms such as fruit fly Drosophila melanogaster (Ferrandon et al., 2007), horseshoe crab, crayfish or ascidians (Iwanaga and Lee, 2005; Söderhäll, 2010). A substantial progress has been also made in the field of blood feeders, such as mosquitoes (Osta et al., 2004; Hillyer, 2010) and tsetse flies (Lehane et al., 2004). The information on the tick innate immunity is rather fragmentary and allows only approximate comparison with other invertebrates (Sonenshine and Hynes, 2008; Kopacek et al., 2010). Nevertheless, even these scattered data indicate that ticks possess defense mechanisms protecting them against microbial infection (Figure 1). At the cellular level, they comprise phagocytosis, encapsulation and nodulation of foreign elements. The humoral defense is based on a variety of pattern-recognition proteins and effector molecules such as lectins, complement-related molecules and a broad spectrum of common as well as specific antimicrobial peptides (AMPs) (Kopacek et al., 2010). In addition, possibly important but rather unexplored role in the tick defense system is played by the immune molecules of the host origin.

In this review, we will follow the transmission routes of pathogens and subsequently enumerate the potential obstacles they have to evade in the tick body. The general features of tick immunity will be further discussed in relation to our current knowledge of tick interaction with the three most intensively studied agents of tick-borne diseases, represented here by Borrelia spirochete, intracellular rickettsia Anaplasma, and malaria-like protozoa Babesia.

\section{TICK IMMUNE SYSTEM \\ TICK MIDGUT-THE PRIMARY SITE OF TICK-PATHOGEN INTERACTIONS}

Although the midgut of arthropod disease vectors is most likely the principle organ that determines their vector competence, the general knowledge of the mutual interplay between ingested

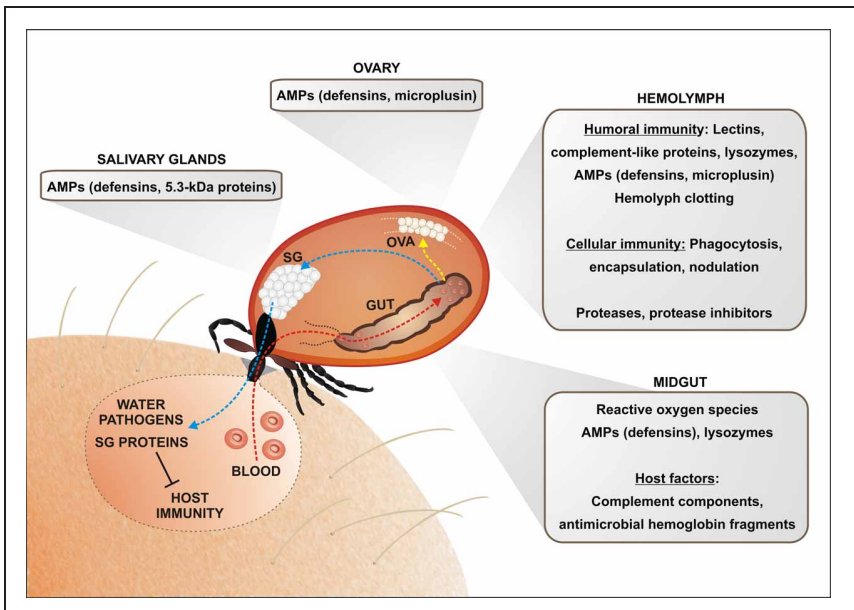

FIGURE 1 | An overview of the tick immune mechanisms and molecules constituting potential barriers for the pathogen

transmission. The pathogen transmission is tightly linked with physiology of blood feeding and tick innate immunity. Ingested blood meal is accumulated in the midgut content (red arrow; only one caecum shown). Hemoglobin and other proteins are taken up by the tick midgut cells and digested intracellularly in the lysosome-like digestive vesicles (Sojka et al., 2013). Liberated amino acids and other compounds are transported to the peripheral tissues and ovaries, supplying mainly egg development (yellow arrow). Importantly, the blood meal is concentrated by reabsorption of excessive water, which is spitted back into the wound by the action of salivary glands (blue arrow). Tick saliva contains a great variety of anti-coagulant, immunomodulatory and anti-inflammatory molecules that facilitate pathogen acquisition and transmission. The ingested pathogens have to survive the period between detachment and subsequent feeding of the next tick developmental stage and overcome several obstacles on its route through the tick body. In the midgut, tick may utilize some of the host immune molecules (e.g., complement system) for its own defense against intestinal inhabitants. Hemoglobin fragments, derived from the host hemoglobin, are secreted into the midgut lumen and exert strong antimicrobial activity. Tick midgut tissue also expresses a variety of endogenous AMPs, which sustain the midgut microbes at a tolerable level. An important, but still poorly understood, role is most likely played by the maintenance of the redox homeostasis in the tick midgut. Pathogens intruding into the tick hemocoel can be phagocytosed by tick hemocytes or destroyed by effector molecules of the humoral defense system, comprising AMPs, components of the primordial complement system (thioester-containing proteins (TEPs), convertase-like factors and fibrinogen-related lectins (FREPs). Ticks probably possess a mechanism of hemolymph clotting, but genes/proteins putatively involved in the activation of prophenoloxidase cascade leading to melanization have not yet been identified in any tick species. Tick salivary glands express also a variety of AMPs, which may impair pathogen acquisition and persistence in the tick, as demonstrated for the 5.3-kDa antimicrobial peptides and their role in the defense against Anaplasma infection (Liu et al., 2012). Abbreviations: GUT, midgut; OVA, Ovary; SG, salivary glands.

pathogen, commensal microflora and tick itself is still inadequate. Unlike in mosquitoes and other insect blood feeders, the microbes ingested by ticks are not in direct contact with digestive proteases secreted into the lumen and the highly nutritious broth of concentrated blood proteins, neutral $\mathrm{pH}$ and long-term storage present an ideal environment for microbial proliferation. Therefore, ticks have to possess efficient defense mechanisms which maintain the intestinal microflora at tolerable level. 
Two recent high-throughput mapping projects of the microflora (microbiome) by the next generation sequencing were carried out in two tick species, R. microplus (Andreotti et al., 2011) and Ixodes ricinus (Carpi et al., 2011). These studies revealed an extreme diversity of the bacterial community (more than hundred different organisms identified in one tick species), which apparently reflects tick geographical and environmental origin as well as developmental stage. However, encounter with a microbe, which a tick hardly meets in nature, could have a fatal consequence because of the lack of effective defense. A good example is the artificial infection of soft tick, Ornithodoros moubata, with the Gram (-) bacterium, Chryseobacterium indologenes (Buresova et al., 2006), which resulted in rapid tick death. Although this soft tick secretes into the midgut lumen at least two kinds of antimicrobial compounds protecting against Gram (+) bacteria, lysozyme (Kopacek et al., 1999; Grunclova et al., 2003) and defensins (Nakajima et al., 2001, 2002), these molecules apparently fail to protect the ticks against some Gram (-) bacteria. Defensins have been also frequently reported to be expressed in the midgut tissues of hard ticks (Hynes et al., 2005; Rudenko et al., 2005; Zhou et al., 2007), but their secretion and antimicrobial activity in the midgut lumen has not yet been unambiguously demonstrated. A defensin-related molecule named longicin, expressed in the midgut of Haemaphysalis longicornis, was reported to be active against a variety of microbes including Gram (+) and Gram (-) bacteria, fungi and various Babesia species (Tsuji et al., 2007) (see also below).

A specific role of the midgut defense against Gram (+) and some fungi is played by the antimicrobial activity of large peptides derived from the host hemoglobin (hemocidins). The antibacterial hemoglobin fragments were initially isolated from the midgut contents of the cattle tick R. microplus (Fogaca et al., 1999) and later also identified in the midgut of other soft and hard tick species (Nakajima et al., 2003; Sonenshine et al., 2005). The generation of antimicrobial hemoglobin fragments most likely occurs in the digestive cells during the initial phase of hemoglobin digestion by the synergic action of cathepsin D-type and cathepsin L-type aspartic and cysteine peptidases, respectively (Horn et al., 2009; Cruz et al., 2010).

Hemoglobin digestion and the concomitant process of heme detoxification via hemosome formation (Lara et al., 2003) is necessarily associated with the maintenance of the redox homeostasis in the tick midgut. Although this process is virtually unknown in ticks, the paradigm to follow is the recent seminal finding on the importance of redox balance in the mosquito midgut epithelial immunity. In the malaria vector Anopheles gambiae, a tandem of heme peroxidase and dual oxidase (Duox) catalyzes formation of dityrosine network between the midgut epithelium and lumen. This network prevents delivery of the epithelial immunity elicitors and ultimately results in up-regulation of intestinal microflora and Plasmodium infection in the lumen (Kumar et al., 2010). Heme peroxidase and NADPH oxidase 5 (Nox5) were further shown to mediate the epithelial nitration of Plasmodium ookinetes and hereby their opsonization for subsequent lysis by the complement-like action of thioester-containing protein TEP1 (Oliveira Gde et al., 2012). The redox situation may also indirectly affect the pathogen transmission by changing its balance with other microflora present in the midgut. An example, how the midgut microflora determines the competence of A. gambiae and malaria parasites was reported recently, showing that ROS produced by the mosquito midgut dweller Enterobacter sp. interfere with Plasmodium development (Cirimotich et al., 2011). The interrelationship between the redox balance and intestinal microflora could be quite complex, as demonstrated using sugar vs. blood fed mosquitoes Aedes aegypti (Oliveira et al., 2011). The presence of heme in the mosquito diet caused a significant decrease of ROS levels, resulting in consequent expansion of midgut bacteria. This phenomenon was interpreted as a result of the mosquito adaptation against the high oxidative stress potentially caused by reaction of pro-oxidative heme with high levels of continuously produced ROS (Oliveira et al., 2011).

By contrast, very little is known about the maintenance of redox homeostasis in the tick midgut except for one report showing the role of catalase in the regulation of the oxidative stress in the cattle tick $R$. microplus (Citelli et al., 2007) and the seminal work on the heme-detoxification pathway described in the same species (Lara et al., 2003, 2005). Nevertheless, the genomic and transcriptomics data from other tick species suggest that ticks do maintain the redox homeostasis in their midguts as they possess ROS-generating enzymes, such as NOX5 or DUOX, and arsenal of antioxidant enzymes and radical scavengers comprising catalases, glutathione- and thioredoxin peroxidases, glutathione S-transferases, and selenoproteins (Anderson et al., 2008; Megy et al., 2012). Thus, the framework of redox balance and its direct or indirect impact on the persistence of pathogens in the tick midgut offers almost unlimited inspiration for the further research.

\section{IMMUNE REACTIONS WITHIN THE TICK HEMOLYMPH}

The major portion of our knowledge on the tick innate immunity is associated with cellular and humoral immune responses within the tick hemocoel. The volume of tick hemolymph increases linearly during the tick feeding from about $2-3 \mu \mathrm{l}$ in unfed to almost $150 \mu \mathrm{l}$ in fully engorged females, as demonstrated for Dermacentor andersoni (Kaufman and Phillips, 1973). At least three types of hemocytes, namely plasmatocytes, granulocytes I and granulocytes II, have been recognized in the hard and soft ticks, out of which the former two are phagocytic (Sonenshine, 1991; Borovickova and Hypsa, 2005). Several studies demonstrated the capability of hemocytes from different tick species to engulf foreign material and different microbes (Inoue et al., 2001; Loosova et al., 2001; Buresova et al., 2006). In addition, it was demonstrated that phagocytosis of microbes by the tick hemocytes is associated with humoral defense mechanisms, such as the production of ROS (Pereira et al., 2001) or complement-like molecules (Buresova et al., 2009, 2011). The process of hemocytic encapsulation of artificial implants, possibly linked with hemolymph coagulation and cellular response against Escherichia coli resembling nodulation, was reported to occur in the hemocoel of Dermacentor variabilis (Eggenberger et al., 1990; Ceraul et al., 2002).

Of special interest is the phagocytosis of tick-transmitted pathogens, such as Borrelia spirochetes, which seem to be 
engulfed at least in part by the process of "coiling" phagocytosis (Rittig et al., 1996). A comparison of the phagocytic and borreliacidal activity against $B$. burgdorferi injected into the hemocoel of natural vector, I. scapularis and a refractory tick D. variabilis, revealed much stronger immune response against the spirochetes in the latter immunocompetent tick species (Johns et al., 2000, 2001a). On the other hand, it was recently shown that infection of $I$. scapularis hemocytes by A. phagocytophilum is mediated by the protein named P11 and is required for successful migration of the pathogen from the midgut to salivary glands (Liu et al., 2011), meaning that phagocytosis or engulfment of the pathogen by tick hemocytes does not necessarily cause its elimination. This rise an interesting question whether at least some of the tick-transmitted pathogens may take an advantage of being engulfed by tick hemocytes to hide from the attack of humoral immune responses in the hemocoel.

Effector molecules of several types have been described in the tick hemolymph, out of which reports on tick defensins are the most frequent since they have been identified in a number of hard and soft tick species (Chrudimska et al., 2010; Kopacek et al., 2010). Moreover, the recent analysis of I. scapularis genome revealed an extensive expansion of genes encoding for defensins and defensin-like peptides divided into two multi-gene families referred to as scapularisins and scasins, respectively (Wang and Zhu, 2011). Typical mature defensins are $\sim 4 \mathrm{kDa}$ cationic peptides with a conserved pattern of six paired cysteins, derived by C-terminal cleavage after the furin (RVVR) motif from $\sim 8 \mathrm{kDa}$ pre-prodefensin. Tick defensins are usually active against Gram $(+)$ bacteria and their interactions with transmitted pathogens [except for the above mentioned longicin (Tsuji et al., 2007)] have not been yet unequivocally demonstrated. Varisin, a defensin isolated from the hemolymph of D. variabilis, exerted a borreliacidal effect in combination with lysozyme (but not alone), which may in part explain the incompetence of this species to sustain $B$. burgdorferi spirochetes (Johns et al., 2001b). Interestingly, depletion of varisin from the $D$. variabilis hemolymph using RNA interference resulted in the significant reduction of Anaplasma marginale infection, indicating that the impact of defense mechanisms on a certain pathogen might be quite complex and not always predictable (Kocan et al., 2008b, 2009).

In addition to defensins, ticks possess a specific class of histidine- and cysteine-rich antimicrobial peptides of size about $10 \mathrm{kDa}$, namely hebraein identified in Amblyoma hebraeum (Lai et al., 2004) and microplusin isolated from the hemolymph of R. microplus (Fogaca et al., 2004). Unlike defensins, which kill bacteria in a detergent-like manner by disruption of bacterial membranes, the bacteriostatic effect of microplusin is based on its capacity to sequester copper required mainly for bacterial respiration (Silva et al., 2009). Another cysteine-rich antimicrobial peptide, unrelated to microplusin and referred to as ixodidin, was isolated from $R$. microplus hemocytes and its antibacterial activity was proposed to be linked to the inhibitory activity against serine proteases by yet unknown mechanism (Fogaca et al., 2006).

The process of self/nonself recognition within the tick hemolymph is believed to involve the interaction of tick lectins and carbohydrates associated with the invading microbes (PAMPs or pathogen-associated molecular patterns). The activity of lectins/hemagglutinins with preferential binding specificity for $\mathrm{N}$-acetyl-D-hexosamines, sialic acids and glycoconjugates have been identified in the hemolymph of several hard and soft tick species (Grubhoffer et al., 2008; Sterba et al., 2011) and is mainly attributed to the presence of fibrinogen-related proteins (FREPs) related to Dorin $\mathrm{M}$, isolated and characterized from the soft tick O. moubata (Kovar et al., 2000; Rego et al., 2006). In contrast to mammalian ficolins, Dorin M lacks the N-terminal collagen-like domain and is closely related to the lectins of tachylectin-5 type known to function as pattern recognition molecules in the horseshoe crab immune system (Gokudan et al., 1999; Kawabata and Tsuda, 2002; Ng et al., 2007). The genomes of I. scapularis and I. ricinus contain genes encoding for a variety of FREPs named Ixoderins that can be phylogenetically divided into three major groups (Rego et al., 2005; Kopacek et al., 2010). Although the role of FREP family members in the invertebrate immunity may be multifunctional, as recently suggested for gastropod mollusk (Hanington and Zhang, 2011), we hypothesize that at least some tick FREPs play a role in activation of tick complement system, components of which have been identified in ticks (Kopacek et al., 2012).

Ticks are unique among other invertebrates in that they possess representatives of all major classes of thioester-containing proteins (TEP) known in vertebrates and arthropods: (1) molecules related to $\alpha 2$-macroglobulins, (2) C3-components of complement system and (3) insect TEPs and (4) macroglobulin complement-related proteins (MCR) (Buresova et al., 2006). The pan protease inhibitors of $\alpha_{2}$-macroglobulin type were reported to be present in the hemolymph of soft and hard ticks (Kopacek et al., 2000; Saravanan et al., 2003; Buresova et al., 2009), where they presumably protect the ticks against undesired proteolytic attack of endogenous as well as exogenous proteases including those of invading microbes. The inhibition of metalloproteases secreted by the Gram (-) bacterium $C$. indologenes was shown to be functionally linked with phagocytosis of this bacteria by the tick hemocytes (Buresova et al., 2009). Further functional study of the tick TEPs suggested that phagocytosis of different bacteria by the tick hemocytes depends on non-redundant involvement of various tick TEPs with a central role of C3-like molecules (Buresova et al., 2011). Although nothing is known about interaction of the tick TEPs with tick-transmitted pathogens, the paradigm of $A$. gambiae TEP1 as a complement-like molecule, which determines the mosquito competence to Plasmodium parasites (Blandin et al., 2004, 2008), should stimulate further research in this area. In addition to the TEP family, genome of I. scapularis contains genes encoding for putative C3 convertases (Kopacek et al., 2012) having the multi-domain architecture similar to that of factor C2/Bf and LPS-sensitive Factor C activating the ancient complement-like system in the horseshoe crab (Zhu et al., 2005; Ariki et al., 2008). These preliminary results suggest that ticks possess features of a primitive complement system, which evolved on Earth at least one billion years ago (Nonaka and Kimura, 2006).

The existence of tick molecule related to the horseshoe crab Factor C, which primarily serves to trigger the limulus clotting cascade upon recognition of bacterial endotoxins (Kawabata, 
2010), may suggest that ticks possess also a system for hemolymph coagulation. This suggestion was in part corroborated by the high throughput screening of immune-responsive genes in $D$. variabilis challenged with different bacteria. The most inducible immune gene found among others was transglutaminase, which acts as a crosslinking enzyme in the terminal phase of clotting mesh formation (Jaworski et al., 2010). However, with a possible exception of the previous observation, where a fibrous matrix was formed around the Epon-Araldite particles implanted under D. variabilis cuticle (Eggenberger et al., 1990), a convincing evidence of hemolymph clotting in ticks is still missing.

In contrast to other arthropods, ticks most likely lack the prophenoloxidase (PPO) activation system leading to melanization, because no PPO-related gene has been yet identified neither in the genome of I. scapularis (Megy et al., 2012) nor within the extensive EST datasets from other tick species (Kopacek et al., 2010).

\section{IMMUNE REACTIONS WITHIN THE SALIVARY GLANDS}

The tick salivary glands and components of tick saliva have been investigated foremost for their indispensable role in the modulation of host hemostasis, inflammation and immune response at the tick-host interface (Francischetti et al., 2009). The increasing number of salivary glands transcriptomes (sialomes) from the hard and soft ticks revealed the expression of a various AMPs, such as defensins, microplusin/hebraein and lysozymes, in this tissue (Mans et al., 2008; Karim et al., 2011). A defensin-like peptide named longicornisin was purified from the salivary glands of H. longicornis (Lu et al., 2010) and two different antimicrobial peptides unrelated to any known AMPs designated as Ixosin and Ixosin B were isolated from the salivary glands of Ixodes sinensis (Yu et al., 2006; Liu et al., 2008). However, it still has not been demonstrated whether these salivary glands AMPs are secreted into the tick saliva or hemolymph and if they directly interact with pathogens. The only exception is the $5.3-\mathrm{kDa}$ antimicrobial protein, referred to as ISAMP and isolated from the saliva of $I$. scapularis, which exerts activity against Gram (-) and Gram (+) bacteria (Pichu et al., 2009). The transcripts encoding the family of secreted $5.3-\mathrm{kDa}$ proteins were previously described to be significantly enriched in the transcriptome of $I$. scapularis nymphs infected with B. burgdorferi (Ribeiro et al., 2006). More recently, it was demonstrated that the $5.3-\mathrm{kDa}$ family members were markedly upregulated in the salivary glands and hemocytes during $A$. phagocytophilum infection and were involved in the I. scapularis defense against this pathogen. Intriguingly, they were also shown to be effector molecules regulated by the JAKSTAT pathway (Liu et al., 2012) and although the I. scapularis genome contains also components of the putative Toll and Imd immune signaling pathways (Megy et al., 2012; Severo et al., 2013), the $5.3-\mathrm{kDa}$ family regulation by JAK/STAT is the only so far described case of tick antimicrobial response controlled by a signaling pathway.

\section{RNA INTERFERENCE-AN ANTIVIRAL DEFENSE IN TICKS}

The RNA interference (RNAi) is an ancient mechanism evolved for the inhibition of foreign genetic elements and precise regulation of the endogenous genes during organism development
(Myers and Ferrell, 2005). The RNAi seems to work very well in the tick tissues (De La Fuente et al., 2007b) and the genome of I. scapularis contains all components important for the endogenous and exogenous RNAi machinery including dicers, argonauts, dsRNA binding proteins, exonucleases and surprisingly also RNA-dependent RNA polymerases (Kurscheid et al., 2009). The discovery that plant viruses encoded suppressors of the gene silencing machinery provided a strong support for RNAi function as a natural defense mechanism against viruses (Lindbo et al., 1993; Ratcliff et al., 1999). It was shown that viral proteins identified as suppressors in plants and insect cells were able to abrogate RNA silencing also in the tick cells (Garcia et al., 2006). In the context of tick immunity, we can speculate that RNAi could interfere directly with the viral infection or regulate production of antimicrobial peptides through the expression of microRNAs.

\section{TICK INTERACTIONS WITH TRANSMITTED PATHOGENS BORRELIA}

Lyme disease is an emerging human tick-borne disease of temperate climates with a concurrent distribution spanning North America and Eurasia. It is caused by Borrelia spirochetes related to Treponema and Leptospira, mainly by Borrelia burgdorferi sensu stricto in the US. and B. burgdorferi sensu stricto, B. garinii, and B. afzelii in Europe (Radolf and Samuels, 2010). Borreliosis in humans affects multiple body systems, producing a range of potential symptoms (Burgdorfer et al., 1989). The classical sign of early infection is circular, expanding, skin rash at the tick bite site called erythema migrans. Treatment with antibiotics is effective at this stage of infection. When left untreated, the spirochetes disseminate throughout the body and are associated with arthritis (B. burgdorferi sensu stricto), neurological symptoms (B. garinii) or dermatitis (B. afzelii) (Stanek et al., 2012). Although Lyme disease is intensively studied, an effective vaccine is still not available and annual incidence in many countries continues leading over other human vector-borne diseases (Bacon et al., 2008).

Borrelia spirochetes survive in an enzootic cycle involving three-host Ixodes ticks and small animals like rodents, birds and lizards (Steere et al., 2004). The spirochetes are usually not detected in larger mammals, which are essential in the tick life cycle as a source of sufficient amount of blood for feeding females (adult female of Ixodes ticks can take in total about one milliliter of blood Balashov, 1972), but complement system of the vertebrate innate immunity lyses most of the bacteria (De Taeye et al., 2013). Humans are not able to efficiently kill the pathogens and often get infected. However, they are mostly dead-end hosts for both the ticks and the pathogens. Transovarial transmission of Borrelia in ticks is not likely (Rollend et al., 2013) and people can contract Lyme disease only by feeding of infected nymphs or adults, where nymphs play a key role in the epidemiology of disease because of their small size and relatively short feeding time.

The interplay between tick proteins, Borrelia spirochetes and hosts has been mapped by transcriptomics and proteomics studies (Narasimhan et al., 2007a), antibody-screening assays (Das et al., 2001) and yeast-surface displays (Schuijt et al., 2011b). Several tick genes have been identified as crucial for acquisition of the infection in ticks, Borrelia persistence in the midgut 
and transmission into the next host during subsequent feeding (Figure 2 and Table 1). Borrelia colonization of the tick midgut lumen and their persistence until the next feeding is crucial process for the successful transmission of the parasite. Borrelia outer surface protein A (OspA) (De Silva et al., 1996), which is expressed predominantly inside the tick vector, is essential for pathogen adherence to the midgut cells during the acquisition phase and plays a significant role in the pathogen persistence. During the subsequent feeding, OspA expression is suppressed, but upregulated expression of OspC facilitates invasion of the tick salivary glands and transmission to the new host (Schwan et al., 1995). Tick protein called TROSPA (tick receptor for OspA)

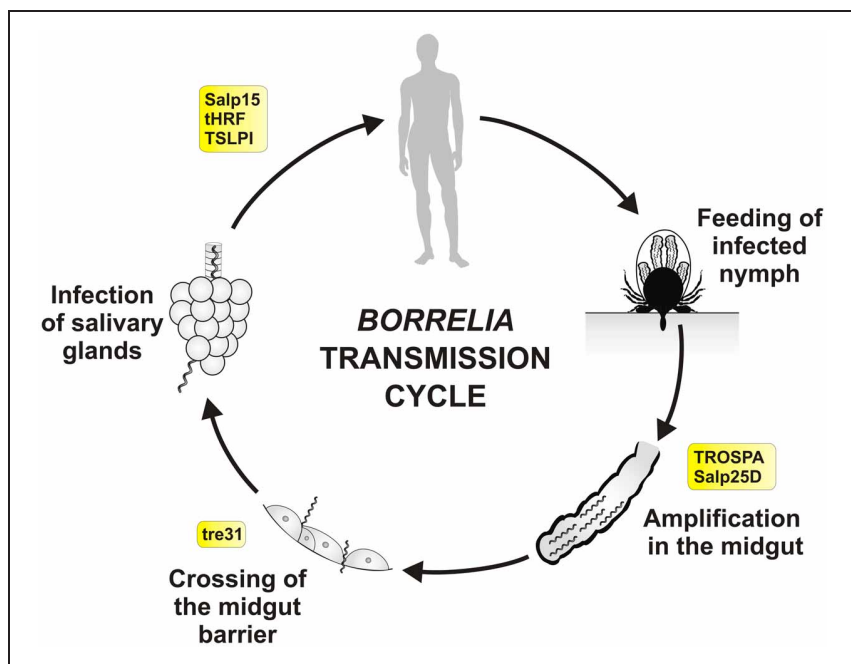

FIGURE 2 | Tick molecules involved in Borrelia transmission. Schematic diagram representing general stages of $B$. burgdorferi sensu lato infection and transmission in the /xodes nymph, the most important developmental stage for human infection. Tick molecules, for which interference with Borrelia acquisition, persistence and/or transmission have been proved by genetic tests, are shown in rectangles (see text and the Table $\mathbf{1}$ for their function and references). Borrelia spirochetes, that persisted in the tick midgut after the previous feeding (transstadial transmission), multiply rapidly within the newly engorged blood. They remain immobile and attached to the midgut cells. Around 53-72 $\mathrm{h}$ after the placement spirochetes become motile and swiftly cross the midgut barrier (between the cells), enter the hemolymph, salivary glands and via the saliva they infect new host (Ohnishi et al., 2001; Dunham-Ems et al., 2009).

Transovarial transmission of Borrelia does not occur and newly hatched larvae are not infectious. has been found to be implicated in the binding of OspA ( $\mathrm{Pal}$ et al., 2004). TROSPA is specifically expressed in the midgut and its mRNA levels increase following the spirochete infection and decrease in response to engorgement. Importantly, interference with TROSPA expression by RNAi or its saturation by TROSPA antisera reduces Borrelia adherence to the midgut surface, preventing pathogen colonization of the vector and reducing its transmission (Pal et al., 2004).

An antibody-screening assay performed on rabbit sera with acquired resistance to the tick bites after I. scapularis infestation identified salivary gland protein called Salp25D (Das et al., 2001). Salp25D encodes for a glutathione peroxidase, is upregulated upon feeding, and silencing of this gene by RNAi or immunization of mice with the recombinant protein impairs spirochete acquisition by ticks (Narasimhan et al., 2007b). Thus, Salp25D is most likely important for quenching the reactive oxygen species released from the activated neutrophils and hereby protects Borrelia during acquisition and colonization of the tick midgut.

During the tick feeding, Borrelia spirochetes, which multiplied previously in the midgut content, cross midgut barrier (between the cells) to get into the hemolymph and salivary glands (De Silva and Fikrig, 1995; Hojgaard et al., 2008; Dunham-Ems et al., 2009). Borrelia enolase, an enzyme found on the surface of spirochetes, was shown to bind host plasminogen and facilitate dissemination of Borrelia in the ticks and host (Coleman et al., 1995, 1997). In the later study, yeast surface display approach identified that Borrelia outer-surface lipoprotein BBE31 interacted with the tick protein called tre31 (Zhang et al., 2011). Expression of tre31 is induced in the midgut upon Borrelia infection and silencing of tre 31 by RNAi or blocking of BBE31 using mice antibodies decreases spirochete burden in the hemolymph and salivary glands of feeding ticks.

It has been shown before that proteins contained in the tick saliva had strong pharmacological properties, targeting coagulation, platelet aggregation, vasoconstriction (Chmelar et al., 2012) and complement system (De Taeye et al., 2013). Salp15 is a salivary gland protein with remarkable immunosuppressive properties, which is bound by Borrelia OspC surface protein during host invasion and protects the spirochetes from antibody-mediated killing (Ramamoorthi et al., 2005). Its expression is upregulated in salivary glands upon Borrelia infection and silencing of Salp15 by RNAi dramatically reduces the capacity of spirochetes to infect mice. Moreover, antibodies raised against tick Salp15 protect

Table 1 | Tick molecules interfering with Borrelia acquisition, persistence and/or transmission.

\begin{tabular}{|c|c|c|c|}
\hline Name & Supposed function & RNAi effect on the pathogen & References \\
\hline Tick receptor for OspA (TROSPA) & Unknown & Reduced acquisition & Pal et al., 2004 \\
\hline Salivary protein 15 (Salp15) & $\begin{array}{l}\text { Inhibition of the host complement } \\
\text { system }\end{array}$ & Decreased transmission & Ramamoorthi et al., 2005 \\
\hline Salivary protein 25D (Salp25D) & Glutathione peroxidase & Decreased acquisition & Narasimhan et al., 2007b \\
\hline Tick histamine release factor (tHFR) & Stimulation of histamine release & Decreased transmission & Dai et al., 2010 \\
\hline Tick receptor of BBE31 (tre31) & Unknown & Reduced persistence & Zhang et al., 2011 \\
\hline $\begin{array}{l}\text { Tick salivary lectin pathway inhibitor } \\
\text { (TSLPI, P8) }\end{array}$ & $\begin{array}{l}\text { Inhibition of the host complement } \\
\text { system }\end{array}$ & $\begin{array}{l}\text { Decreased persistence and } \\
\text { transmission }\end{array}$ & Schuijt et al., 2011a \\
\hline
\end{tabular}


mice from the infection (Dai et al., 2009). Tick salivary lectin pathway inhibitor TSLPI, previously identified by yeast surface display assay as P8 protein with ability to reduce complement killing of Borrelia (Schuijt et al., 2011b), interferes with lectin complement pathway, resulting in impaired neutrophil phagocytosis and chemotaxis (Schuijt et al., 2011a). Silencing of this protein by RNAi or exposure of ticks to TSLPI-immunized mice decreases persistence of Borrelia in nymphs and hampers their transmission, respectively. Tick histamine-release factor tHRF is a saliva protein able to bind host basophils and stimulate histamine release (Dai et al., 2010). This property can be exploited by Borrelia spirochetes for host infection. Expression of tHRF is upregulated in Borrelia-infected ticks and silencing of this gene by RNAi or tHRF blocking by antibodies reduce tick feeding and decrease spirochete burden in mice. The last molecule that should be mention is tick salivary protein named Salp20, which is an inhibitor of alternative complement pathway and partially protects serum sensitive species of Borrelia from lysis (Tyson et al., 2007) by displacing properdin from C3 convertase (Tyson et al., 2008). However, functional genetic studies are needed to prove its role in vivo.

\section{ANAPLASMA}

Anaplasmosis is considered as one of the most important vectorborne diseases of livestock (Kocan et al., 2010). The genus Anaplasma (Rickettsiales: Anaplasmataceae) includes six species of obligate intracellular bacteria, closely related to Ehrlichia, Wohlbachia, and Neorickettsia, occurring within the membranebound vacuoles called colonies in the host cytoplasm (Dumler et al., 2001; Kocan et al., 2008a). The Anaplasma rickettsiae preferably infect vertebrate red blood cells, however A. phagocytophilum attacks host neutrophils.

A. phagocytophilum infects a wide range of animals. It is responsible for the human granulocytic anaplasmosis (HGA), an emerging disease in the US, Europe and Asia, tick-borne fever in ruminants and equine and canine anaplasmosis (Woldehiwet, 2010). Three Anaplasma species exclusively infect ruminants: A. marginale, A. centrale, and A. ovis. A. centrale is used as life cattle vaccine in some regions, because infection with this parasite results only in mild clinical symptoms and could leave cattle persistently infected but immune against $A$. marginale, the causative agent of bovine anaplasmosis, which causes economic losses to the cattle industry worldwide. A. ovis is infective for sheep and wild ruminants, but infections are usually asymptomatic (Kocan et al., 2010). Also included in the genus Anaplasma are A. bovis and A. platys, which infect cattle and dogs, respectively.

All Anaplasma species are transmitted by Ixodid ticks, although tick transmissibility of $A$. centrale has been recently questioned (Shkap et al., 2009). The transmission cycle has been most extensively studied for A. marginale (Kocan et al., 1986, 1992a,b, 2008a). The developmental cycle in ticks is well coordinated with feeding and two Anaplasma morphotypes, reticulate (cell-dividing form) and dense core (infective form), can be found at each site of development (Kocan et al., 2010). Transovarial transmission of Anaplasma spp. from female ticks to their progeny does not occur. Therefore, ticks must acquire infection during blood feeding and the transmission cycles of these bacteria in nature are dependent upon the presence of infected reservoir hosts. Transmission by one-host ticks is probably accomplished by males, which can feed repeatedly and transfer between hosts (Sonenshine, 1991).

It has been shown that Anaplasma spp. modulate gene expression in ticks (De La Fuente et al., 2007a; Kocan et al., 2008a; Zivkovic et al., 2009; Sultana et al., 2010; Villar et al., 2010a,b), although differences may exist between species (Zivkovic et al., 2009). Functional studies of tick-Anaplasma interactions have shown how tick genes may affect bacterial infection (Figure 3 and Table 2). Four differentially regulated genes/proteins, glutathione S-transferase (GST), salivary selenoprotein M (SelM), vATPase, and ubiquitin have been identified by suppression-subtractive hybridization and differential in-gel electrophoresis analyses using tick IDE8 cells infected with A. marginale (De La Fuente et al., 2007a). Glutathione S-transferases are intracellular enzymes with various functions, mostly accompanying cellular detoxification, but also signaling (Oakley, 2011). Selenoproteins are selenocysteine-containing proteins and important antioxidants (Reeves and Hoffmann, 2009). Vacuolar $\mathrm{H}^{+}$ATPases are membrane proteins acidifying a wide array of intracellular organelles by pumping protons across the plasma membranes (Nelson, 2003). Finally, ubiquitins are small regulatory proteins, involved

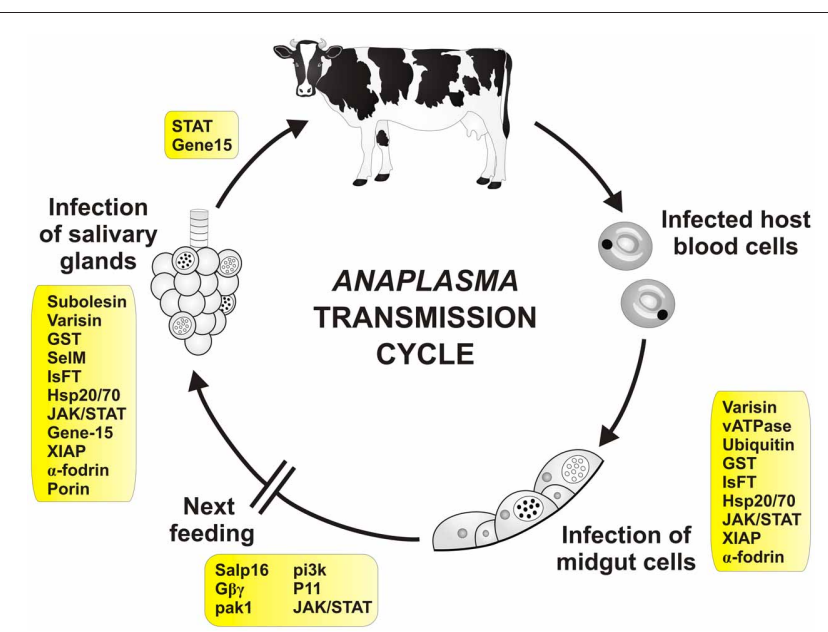

FIGURE 3 | Tick molecules involved in Anaplasma transmission. Schematic diagram representing general stages of Anaplasma infection and transmission (Kocan et al., 2008a). Tick genes, for which interference with Anaplasma acquisition and/or transmission have been proved by genetic tests, are shown in rectangles (see text and the Table 2 for their function and references). Infected red blood cells (neutrophils for $A$.

phagocytophilum) are engorged by the tick during blood meal. The released bacteria infect tick midgut cells and develop reticulate (cell-dividing; open circle) and dense core (infective; filled circle) forms of colonies inside the cells. During the next feeding, bacteria are released from the cells and infect other tissues including salivary glands. Here, they multiply inside the cells and are released into the saliva and transferred into the new host. Infection of tick hemocytes is required for the pathogen migration from the midgut to the salivary glands (Liu et al., 2011). Transovarial transmission of Anaplasma does not seem to occur. Transmission in one-host ticks is probably accompanied by tick males, which can feed repeatedly and transfer between hosts. 
Table 2 | Tick molecules interfering with Anaplasma acquisition and/or transmission.

\begin{tabular}{|c|c|c|c|}
\hline Name & Supposed function & RNAi effect on the pathogen & References \\
\hline Salivary protein 16 (Salp16) & Unknown & Decreased acquisition & Sukumaran et al., 2006 \\
\hline Subolesin (SUB) & $\begin{array}{l}\text { Component of the immune signaling } \\
\text { pathways }\end{array}$ & Decreased acquisition & $\begin{array}{l}\text { De La Fuente et al., 2006, 2008; Merino } \\
\text { et al., 2011; Busby et al., } 2012\end{array}$ \\
\hline Varisin & Defensin & Decreased acquisition & Kocan et al., 2008b \\
\hline Vacuolar $\mathrm{H}^{+}$ATPase (vATPase) & Acidification of vesicles & Decreased acquisition & $\begin{array}{l}\text { De La Fuente et al., 2007a; Kocan et al., } \\
2009\end{array}$ \\
\hline Ubiquitin & Protein degradation & Decreased acquisition & $\begin{array}{l}\text { De La Fuente et al., 2007a; Kocan et al., } \\
2009\end{array}$ \\
\hline Glutathione S-transferase (GST) & Detoxification and signaling & Decreased acquisition & $\begin{array}{l}\text { De La Fuente et al., 2007a; Kocan et al., } \\
2009\end{array}$ \\
\hline Salivary selenoprotein M (SeIM) & Protection against oxidative stress & Decreased acquisition & $\begin{array}{l}\text { De La Fuente et al., 2007a; Kocan et al., } \\
2009\end{array}$ \\
\hline$\alpha-1,3$ fucosyltransferase (IsFT) & Glycosylation of proteins & Decreased acquisition & Pedra et al., 2010 \\
\hline $\begin{array}{l}\text { G protein-coupled receptor } G \beta \gamma \\
\text { subunits }(G \beta \gamma)\end{array}$ & Signal transduction & Decreased acquisition & Sultana et al., 2010 \\
\hline Phosphoinositide 3-kinase (pak1) & Cytoskeletal reorganization and signaling & Decreased acquisition & Sultana et al., 2010 \\
\hline p21-activated kinase (pi3k) & Cytoskeletal reorganization and signaling & Decreased acquisition & Sultana et al., 2010 \\
\hline Protein $11(\mathrm{P} 11)$ & Unknown & Decreased acquisition & Liu et al., 2011 \\
\hline Heat-shock protein 20 (Hsp20) & Cellular stress response & Increased acquisition & Busby et al., 2012 \\
\hline Heat-shock protein 70 (Hsp70) & Cellular stress response & Decreased acquisition & Busby et al., 2012 \\
\hline Janus kinase (JAK) & $\begin{array}{l}\text { Component of JAK/STAT signaling } \\
\text { pathway }\end{array}$ & Increased acquisition & Liu et al., 2012 \\
\hline $\begin{array}{l}\text { Signal transducer and activator of } \\
\text { transcription (STAT) }\end{array}$ & $\begin{array}{l}\text { Component of JAK/STAT signaling } \\
\text { pathway }\end{array}$ & $\begin{array}{l}\text { Increased acquisition and } \\
\text { transmission }\end{array}$ & Liu et al., 2012 \\
\hline Gene-15 & Antimicrobial peptide & $\begin{array}{l}\text { Increased acquisition and } \\
\text { transmission }\end{array}$ & Liu et al., 2012 \\
\hline $\begin{array}{l}\text { X-linked inhibitor of apoptosis } \\
\text { protein (XIAP) }\end{array}$ & E3 ubiquitin ligase & Increased acquisition & Severo et al., 2013 \\
\hline$\alpha$-fodrin (CG8) & Spectrin $\alpha$-chain & Decreased acquisition & Ayllón et al., 2013 \\
\hline Porin (T2) & $\begin{array}{l}\text { Mitochondrial voltage-dependent } \\
\text { anion-selective channel }\end{array}$ & Decreased acquisition & Ayllón et al., 2013 \\
\hline
\end{tabular}

in an intracellular destruction and recycling of proteins in the proteasome, which is an important process also for the regulation of arthropod immune pathways (Ferrandon et al., 2007). Silencing of GST, vATPase or ubiquitin by RNAi decreases midgut Anaplasma acquisition in D. variabilis males fed on A. marginale infected cows, while silencing of GST or SelM decreases pathogen infection in the salivary glands of infected ticks fed on naïve sheep (De La Fuente et al., 2007a; Kocan et al., 2009). As previously mentioned, silencing of $D$. variabilis defensin named varisin that was shown to be expressed primarily in hemocytes, but also in midgut and other tissues (Hynes et al., 2008), decreased midgut pathogen acquisition in D. variabilis males fed on A. marginale infected cows and decreased infection in salivary glands of infected ticks fed on naïve sheep with obvious morphological abnormalities in bacterial colonies (Kocan et al., 2008b). Moreover, silencing of E3 ubiquitin ligase named x-linked inhibitor of apoptosis (XIAP) increases colonization of I. scapularis midgut cells and salivary glands by A. phagocytophilum, attracting even more attention to the ubiquitination process in ticks (Severo et al., 2013).

Fucosylation, which participates in many pathological processes in eukaryotes, has been shown to be modulated in ticks during Anaplasma infection (Pedra et al., 2010). A. phagocytophilum modulates expression of $I$. scapularis $\alpha-1,3$ fucosyltransferase (IsFT) and uses $\alpha-1,3$-fucosylation process to colonize the tick vector. Silencing of IsFT by RNAi reduces acquisition but not transmission of A. phagocytophilum in ticks.

The arthropod immune responses are generally regulated by Toll, Imd and JAK/STAT pathways (Ferrandon et al., 2007). Janus kinase (JAK)/signaling transducer activator of transcription (STAT) pathway has been shown to play a critical role in the tick defense against Anaplasma (Liu et al., 2012). Silencing of JAK/STAT genes by RNAi in I. scapularis causes burden of A. phagocytophilum in midgut, hemolymph and SG. The gene15 of the salivary glands family encoding a member of $5.3-\mathrm{kDa}$ antimicrobial peptide family is highly induced upon Anaplasma infection and regulated by JAK/STAT pathway. Silencing of gene15 (and also STAT) by RNAi causes increased infection in salivary glands and transmission to the mammalian host.

Salivary protein 16 (Salp16) is an antigen recognized by tickexposed host sera. Silencing of Salp16 by RNAi does not influence A. phagocytophilum acquisition in I. scapularis midgut, but the pathogen is not able to successfully infect the salivary glands (Sukumaran et al., 2006). Furthermore, expression of Salp16 in 
the tick salivary glands is upregulated upon Anaplasma infection. It has been elegantly shown that Salp16 upregulation is not part of the tick defense mechanisms, but that Anaplasma selectively alter Salp16 expression for its benefit (Sultana et al., 2010). A. phagocytophilum infection induces actin phosphorylation, which is dependent on tick p21-activated kinase (ipak1)-mediated signaling. Activity of ipak1 is stimulated via G protein-coupled $G \beta \gamma$ receptor subunits $(\mathrm{G} \beta \gamma)$, which in turn mediate phosphoinositide 3-kinase (pi3k) activation. In association with RNA polymerase II (RNAPII) and TATA box-binding protein, expression of Salp16 is selectively promoted. Silencing of ipak1, G $\beta \gamma$ or pi3k by RNAi reduces actin phosphorylation and Anaplasma acquisition by ticks (Sultana et al., 2010).

Recently, $\alpha$-fodrin (spectrin $\alpha$-chain) and mitochondrial porin (voltage-dependent anion-selective channel) were shown to be involved in A. phagocytophilum infection/multiplication and the tick cell response to infection in I. scapularis (Ayllón et al., 2013). The pathogen presence decreases expression of $\alpha$-fodrin in the tick salivary glands and porin in both the midgut and salivary glands to inhibit apoptosis, subvert host cell defenses and increase infection. In the midgut, $\alpha$-fodrin upregulation was used by the pathogen to increase infection due to cytoskeleton rearrangement that is required for pathogen infection. These results demonstrated that the pathogen uses similar strategies to establish infection in both vertebrate and invertebrate hosts.

After the initial infection of midgut cells, Anaplasma spread to other tick organs. However, the exact mechanism mediating migration to and infection of different tick organs is still not well known. Secreted I. scapularis protein 11 (P11), induced upon A. phagocytophilum infection, was shown to be important for Anaplasma migration from the midgut to the salivary glands, while being engulfed and hidden in the tick hemocytes (Liu et al., 2011). Silencing of P11 by RNAi or blocking the P11 with anti-sera or inhibition of hemocyte phagocytosis by injection of polystyrene beads into the tick hemolymph resulted in decreased Anaplasma infection of the tick salivary glands (Liu et al., 2011).

Tick subolesin (SUB), an ortholog of insect and vertebrate akirins, is possibly involved in several pathways, including innate immune responses, through a regulatory network involving crossregulation between NF- $\mathrm{BB}$ (Relish) and SUB and SUB autoregulation (Naranjo et al., 2013). SUB is down-regulated during A. phagocytophilum infection of tick nymphs, but up-regulated in female midguts and salivary glands infected with A. marginale or A. phagocytophilum (De La Fuente et al., 2006; Galindo et al., 2009; Zivkovic et al., 2010; Merino et al., 2011; Busby et al., 2012). Silencing of SUB by RNAi has strong effect on tick mortality and feeding and causes degeneration of midgut, salivary glands and reproductive organs (De La Fuente et al., 2008). After SUB knockdown, infection with $A$. marginale is significantly reduced in $D$. variabilis male salivary glands, but has only little effect on infection with A. phagocytophilum (De La Fuente et al., 2006; Ayllón et al., 2013). Subolesin has been used for vaccination against tick infestations and pathogen infection (De La Fuente et al., 2011). Although limited success has been obtained in this area, ongoing efforts are focused on the characterization of the Anaplasma-tick interface to develop vaccines for the control of tick infestations and pathogen transmission (De La Fuente, 2012).

\section{BABESIA}

Babesiosis is a tick-borne malaria-like disease affecting health of many animals and reducing cattle production in tropical and subtropical regions worldwide. Moreover, human babesiosis increasingly raises public health concern (Florin-Christensen and Schnittger, 2009). Babesia, the causative agent of babesiosis, is an apicomplexan parasite, which is together with Theileria referred to as piroplasm because of its pear-shape intra-erythrocytic stage. The genus Babesia constitutes paraphyletic group of parasites (described in various hosts with discrepancies in developmental cycles), which can be only distinguished by an appropriate molecular methods (Allsopp and Allsopp, 2006). They multiply in vertebrate erythrocytes (asexual stage) and cause severe symptoms related to their destruction. In the tick (hard tick), the parasite undergo sexual development in the midgut content, multiply in midgut cells and spread to different tissues including the salivary glands and ovary. Most of Babesia, unlike Theileria, are capable of transovarial transmission and newly hatched larvae are infectious to the hosts (Chauvin et al., 2009; Florin-Christensen and Schnittger, 2009).

It has been shown that infection of ticks with Babesia parasite pose negative effect on the tick development (Cen-Aguilar et al., 1998), thus ticks are supposed to evolve defense mechanisms to control Babesia infection and to regulate their mutual interaction. Although genomic sequences of Babesia and tick are available (Pagel Van Zee et al., 2007; Cornillot et al., 2012) and several projects have identified tick genes differently expressed upon Babesia infection (Rachinsky et al., 2007, 2008; Antunes et al., 2012; Heekin et al., 2012), only few tick genes have been shown to be directly implicated in the vector-pathogen interaction (Figure 4 and Table 3). First of them, called longicin (Tsuji and Fujisaki, 2007), is defensin-like protein of H. longicornis exerting anti-microbial and anti-fungal activity. Recombinant longicin was reported to inhibit proliferation of Babesia (Theileria) equi merozoites in in vitro cultures and to reduce parasitemia of mice experimentally infected with B. microti. Moreover, silencing of this gene by RNAi increased number of $B$. gibsoni in the tick midgut content, ovary and laid eggs, pointing to longicin role in the regulation of $H$. longicornis vectorial capacity (Tsuji et al., 2007).

Longipain (Tsuji et al., 2008) is midgut-specific cysteine protease of $H$. longicornis, whose expression is upregulated upon blood feeding. Similarly as for longicin, recombinant protein inhibited proliferation of Babesia (Theileria) equi merozoites in in-vitro cultures and silencing of this gene by RNAi resulted in increased number of parasites in the midgut lumen, ovary, and hatched larvae. In general, inhibition of tick and parasite proteases is of interest as both the tick and the parasite genomes encode for several cysteine proteases important for blood digestion (Sojka et al., 2008) and host invasion (FlorinChristensen and Schnittger, 2009), respectivelly. Addition of various cysteine protease inhibitors into the B. bovis culture resulted in parasite growth inhibition (Okubo et al., 2007). The cysteine proteases inhibitor called cystatin-2 (Hlcyst2) from $H$. longicornis (Zhou et al., 2006) was overexpressed in midgut and hemocytes after Babesia infection. Recombinant HlCyst2 had slight effect on $B$. bovis growth in in vitro assays, but 
its role in the tick infection has never been experimentally examined.

Three tick genes, namely TROSPA, serum amyloid A and calreticulin has been recently identified by cDNA screen as genes upregulated after the tick infection with B. bigemina (Antunes et al., 2012). TROSPA is a midgut receptor with unknown function, which is used by Borrelia spirochete as a docking protein for midgut colonization and spirochete persistence (Pal et al., 2004). Serum amyloid A is a homolog of vertebrate acute phase protein

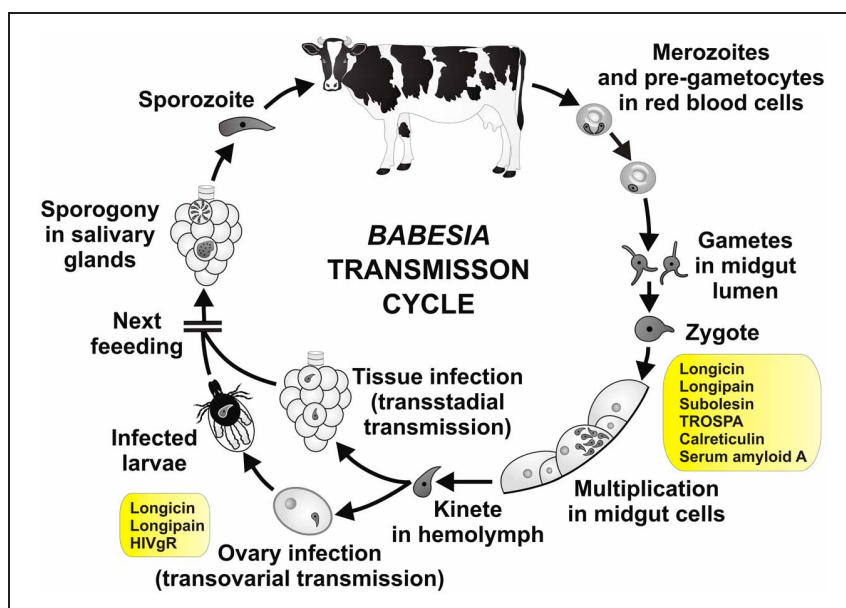

FIGURE 4 | Tick molecules involved in Babesia transmission. Schematic diagram representing general stages of Babesia infection and transmission (Zintl et al., 2003; Chauvin et al., 2009; Florin-Christensen and Schnittger, 2009). Tick genes, for which interference with Babesia acquisition and/or transmission have been proved by genetic tests, are shown in rectangles (see text and the Table 3 for their function and references).

Pre-gametocytes in red blood cells, taken up within the blood meal, develop in the tick midgut content into matured gametocytes and gametes (ray bodies, Strahlenkörper) with distinctive spine-like projections. They fuse and give raise to the spherical spiked zygotes, which invade midgut cells. Inside the midgut cells, the zygotes transform, undergo meiosis and differentiate into motile prolonged kinetes (ookinetes). The kinetes escape the midgut cells, enter the hemolymph and invade other tick tissues, including ovary (transstadial and transovarial transmission, respectively). Here they undergo asexual reproduction and produce sporokinetes, which further spread the infection inside the tick or newly emerged larvae. During the next feeding, the kinetes that invaded salivary glands undergo a final cycle of

multiplication (sporogony) to produce numerous sporozoites, host-invasive stages of the parasite. The sporozoites enter the tick saliva and infect host. reacting to inflammation (Urieli-Shoval et al., 2000). Calreticulin is an intracellular protein with many functions, including calcium binding, protein folding and immune signaling (Wang et al., 2012). Involvement of these genes in Babesia infection has been confirmed by RNAi, where silencing significantly reduced $B$. bigemina numbers in Rhipicephalus annulatus and $R$. microplus (Antunes et al., 2012). Furthermore, RNAi silencing of subolesin (the previously mentioned ortholog of mammalian akirin) or vaccination with recombinant SUB strongly reduced acquisition of B. bigemina by R. microplus fed on an infected cattle (Merino et al., 2011).

Vitellogenin serves as a storage protein and source of amino acids during embryogenesis and its uptake is achieved by a specific vitellogenin receptor, which was identified from $H$. longicornis and shown by RNAi to be indispensable for egg development (Boldbaatar et al., 2008). Interestingly, Babesia DNA was not detected in eggs lays from ticks with silenced vitellogenin receptor previously fed on dogs infected with $B$. gibsoni. This suggests that impairing the vitellogenin uptake interrupt the parasite transovarial transmission.

\section{CONCLUSION-FUTURE PERSPECTIVES}

The overall knowledge of tick innate immunity still lags far beyond the model invertebrate organisms and arthropod disease vectors. However, the availability of $I$. scapularis genome database (Megy et al., 2012), feasibility of functional genomics based on RNAi (De La Fuente et al., 2007b) and extensive number of tissue transcriptomes obtained from a variety of tick species promise to counterbalance experimental difficulties associated with tick handling and manipulation. Furthermore, introduction of the artificial membrane feeding (Krober and Guerin, 2007) extends our possibilities how to simulate the natural infections of ticks without the need of using laboratory animal models. These favorable conditions offer almost unlimited perspectives for the advanced research of the tick immune system and its impact on pathogen transmission. Among others, we can enumerate several high-priority topics, which can significantly aid to our understanding of the tick-pathogen relationship: (1) the role of epithelial immunity and maintenance of the redox balance for the pathogen persistence in the tick midgut; (2) interactions between the pathogens and commensal microflora; (3) tick antimicrobial peptides and their regulation via the Toll, Imd and JAK-STAT signaling pathways; (4) the role of tick primordial

Table 3 | Tick molecules interfering with Babesia acquisition and/or transmission.

\begin{tabular}{|c|c|c|c|}
\hline Name & Supposed function & RNAi effect on the pathogen & References \\
\hline Longicin & Defensin & Increased acquisition and transovarial transmission & Tsuji et al., 2007 \\
\hline Longipain & Cysteine protease & Increased acquisition and transovarial transmission & Tsuji et al., 2008 \\
\hline $\begin{array}{l}\text { H. longicornis vitellogenin receptor } \\
\text { (HIVgR) }\end{array}$ & Uptake of vitellogenin & Decreased transovarial transmission & Boldbaatar et al., 2008 \\
\hline Subolesin (SUB) & $\begin{array}{l}\text { Component of the immune } \\
\text { signaling pathways }\end{array}$ & Decreased acquisition & Merino et al., 2011 \\
\hline Tick receptor for OspA (TROSPA) & Unknown & Decreased acquisition & Antunes et al., 2012 \\
\hline Calreticulin & Protein folding and signaling & Decreased acquisition & Antunes et al., 2012 \\
\hline Serum amyloid $\mathrm{A}$ & Response to inflammation & Decreased acquisition & Antunes et al., 2012 \\
\hline
\end{tabular}


complement system in the immune response against transmitted pathogens; (5) tick molecules involved in the pathogen acquisition, persistence or transmission as vaccine candidates; (6) the detailed description of the pathogen transmission cycles within the tick vector. Taken together, focused research in these areas can lead to the ultimate goal of efficient control of tickborne diseases.

\section{ACKNOWLEDGMENTS}

This work was supported by the Grant Agency of the Czech Republic (grant Nos.: 506/10/2136, 13-11043S; postdoctoral

\section{REFERENCES}

Allsopp, M. T., and Allsopp, B. A. (2006). Molecular sequence evidence for the reclassification of some Babesia species. Ann. N.Y. Acad. Sci. 1081, 509-517. doi: 10.1196/annals.1373.076

Anderson, J. M., Sonenshine, D. E., and Valenzuela, J. G. (2008). Exploring the mialome of ticks: an annotated catalogue of midgut transcripts from the hard tick, Dermacentor variabilis (Acari: Ixodidae). BMC Genomics 9:552. doi: 10.1186/1471-2164-9-552

Andreotti, R., Perez De Leon, A. A., Dowd, S. E., Guerrero, F. D., Bendele, K. G., and Scoles, G. A. (2011). Assessment of bacterial diversity in the cattle tick Rhipicephalus (Boophilus) microplus through tag-encoded pyrosequencing. BMC Microbiol. 11:6. doi: 10.1186/1471-2180-11-6

Antunes, S., Galindo, R. C., Almazan, C., Rudenko, N., Golovchenko, M., Grubhoffer, L., et al. (2012). Functional genomics studies of Rhipicephalus (Boophilus) annulatus ticks in response to infection with the cattle protozoan parasite, Babesia bigemina. Int. J. Parasitol. 42, 187-195. doi: 10.1016/j.ijpara.2011.12.003

Ariki, S., Takahara, S., Shibata, T., Fukuoka, T., Ozaki, A., Endo, Y., et al. (2008). Factor C acts as a lipopolysaccharide-responsive C3 convertase in horseshoe crab complement activation. J. Immunol. 181, 7994-8001.

Ayllón, N., Villar, M., Busby, A. T., Kocan, K. M., Blouin, E. F., Bonzón-Kulichenko, E., et al. (2013). Anaplasma phagocytophilum inhibits apoptosis and promotes cytoskeleton rearrangement for infection of tick cells. Infect. Immun. 81, 2415-2425. doi: 10.1128/IAI.00194-13

Bacon, R. M., Kugeler, K. J., and Mead, P. S. (2008). Surveillance for Lyme disease-United States, 1992-2006. MMWR. Surveill. Summ. 57, 1-9.
Balashov, I. U. S. (1972). A Translation of Bloodsucking Ticks (Ixodoidea)Vectors of Diseases of Man and Animals. College Park, MD: Entomological Society of America.

Blandin, S., Shiao, S. H., Moita, L. F., Janse, C. J., Waters, A. P., Kafatos, F. C., et al. (2004). Complement-like protein TEP1 is a determinant of vectorial capacity in the malaria vector Anopheles gambiae. Cell 116, 661-670. doi: 10.1016/S0092-8674(04)00173-4

Blandin, S. A., Marois, E., and Levashina, E. A. (2008). Antimalarial responses in Anopheles gambiae: from a complement-like protein to a complement-like pathway. Cell Host Microbe 3, 364-374. doi: 10.1016/j.chom.2008.05.007

Boldbaatar, D., Battsetseg, B., Matsuo, T., Hatta, T., Umemiya-Shirafuji, R., Xuan, X., et al. (2008). Tick vitellogenin receptor reveals critical role in oocyte development and transovarial transmission of Babesia parasite. Biochem. Cell Biol. 86, 331-344. doi: 10.1139/O08-071

Borovickova, B., and Hypsa, V. (2005). Ontogeny of tick hemocytes: a comparative analysis of Ixodes ricinus and Ornithodoros moubata. Exp. Appl. Acarol. 35, 317-333. doi: 10.1007/s10493-004-2209-8

Buresova, V., Franta, Z., and Kopacek, P. (2006). A comparison of Chryseobacterium indologenes pathogenicity to the soft tick Ornithodoros moubata and hard tick Ixodes ricinus. J. Invertebr. Pathol. 93, 96-104. doi: 10.1016/j.jip.2006.05.006

Buresova, V., Hajdusek, O., Franta, Z., Loosova, G., Grunclova, L., Levashina, E. A., et al. (2011). Functional genomics of tick thioester-containing proteins reveal the ancient origin of the complement system. J. Innate. Immun. 3, 623-630. doi: 10.1159/000328851

Buresova, V., Hajdusek, O., Franta, Z., Sojka, D., and Kopacek, P. (2009). IrAM-An alpha2macroglobulin from the hard tick

grants No. 13-27630P and No. 13-12816P). Ondřej Hajdušek is further supported by the EU FP7 project MODBIOLIN No. 316304 and Radek Šíma by the project Postdok_BIOGLOBE (CZ.1.07/2.3.00/30.0032) co-financed by the European Social Fund and the state budget of the Czech Republic. The research at the Institute of Parasitology, BC ASCR is covered by RVO 60077344. This work was also supported by grants BFU201123896 and EU FP7 ANTIGONE project number 278976. Nieves Ayllón was funded by MEC, Spain. We acknowledge Marie Hajdušková (www.biographix.cz) for the design of presented figures.

Ixodes ricinus: characterization and function in phagocytosis of a potential pathogen Chryseobacterium indologenes. Dev. Comp. Immunol. 33, 489-498. doi: 10.1016/j.dci.2008.09.011

Burgdorfer, W., Hayes, S. F., and Corwin, D. (1989). Pathophysiology of the Lyme disease spirochete, Borrelia burgdorferi, in ixodid ticks. Rev Infect Dis 11(Suppl. 6), S1442-S1450. doi: 10.1093/clinids/11.Supplement_6.S1442

Busby, A. T., Ayllon, N., Kocan, K. M., Blouin, E. F., De La Fuente, G., Galindo, R. C., et al. (2012). Ex'ion of heat shock proteins and subolesin affects stress responses, Anaplasma phagocytophilum infection and questing behaviour in the tick, Ixodes scapularis. Med. Vet. Entomol. 26, 92-102. doi: 10.1111/j.1365-2915.2011.00973.x

Carpi, G., Cagnacci, F., Wittekindt, N. E., Zhao, F., Qi, J., Tomsho, L. P., et al. (2011). Metagenomic profile of the bacterial communities associated with Ixodes ricinus ticks. PLoS ONE 6:e25604. doi: 10.1371/journal.pone.0025604

Cen-Aguilar, J. F., Rodriguez-Vivas, R. I., Dominguez-Alpizar, J. L., and Wagner, G. G. (1998). Studies on the effect of infection by Babesia sp. on oviposition of Boophilus microplus engorged females naturally infected in the Mexican tropics. Vet. Parasitol. 78, 253-257. doi: 10.1016/S0304-4017 (98)00148-4

Ceraul, S. M., Sonenshine, D. E., and Hynes, W. L. (2002). Resistance of the tick Dermacentor variabilis (Acari: Ixodidae) following challenge with the bacterium Escherichia coli (Enterobacteriales: Enterobacteriaceae). J. Med. Entomol. 39, 376-383. doi: 10.1603/0022-2585-39.2.376

Chauvin, A., Moreau, E., Bonnet, S., Plantard, O., and Malandrin, L. (2009). Babesia and its hosts: adaptation to long-lasting interactions as a way to achieve efficient transmission. Vet. Res. 40, 37. doi: 10.1051/vetres/2009020

Chmelar, J., Calvo, E., Pedra, J. H., Francischetti, I. M., and Kotsyfakis, M. (2012). Tick salivary secretion as a source of antihemostatics. J. Proteomics 75, 3842-3854. doi: 10.1016/j.jprot.2012.04.026

Chrudimska, T., Chrudimsky, T., Golovchenko, M., Rudenko, N., and Grubhoffer, L. (2010). New defensins from hard and soft ticks: similarities, differences, and phylogenetic analyses. Vet. Parasitol. 167, 298-303. doi: 10.1016/j.vetpar.2009.09.032

Cirimotich, C. M., Dong, Y., Clayton, A. M., Sandiford, S. L., SouzaNeto, J. A., Mulenga, M., et al. (2011). Natural microbe-mediated refractoriness to Plasmodium infection in Anopheles gambiae. Science 332, 855-858. doi: 10.1126/science. 1201618

Citelli, M., Lara, F. A., Da Silva Vaz, I. Jr., and Oliveira, P. L. (2007). Oxidative stress impairs heme detoxification in the midgut of the cattle tick, Rhipicephalus (Boophilus) microplus. Mol. Biochem. Parasitol. 151, 81-88. doi: 10.1016/j.molbiopara.2006. 10.008

Coleman, J. L., Gebbia, J. A., Piesman, J., Degen, J. L., Bugge, T. H., and Benach, J. L. (1997). Plasminogen is required for efficient dissemination of $B$. burgdorferi in ticks and for enhancement of spirochetemia in mice. Cell 89, 1111-1119. doi: 10.1016/S0092-8674(00)80298-6

Coleman, J. L., Sellati, T. J., Testa, J. E., Kew, R. R., Furie, M. B., and Benach, J. L. (1995). Borrelia burgdorferi binds plasminogen, resulting in enhanced penetration of endothelial monolayers. Infect. Immun. 63, 2478-2484.

Cornillot, E., Hadj-Kaddour, K., Dassouli, A., Noel, B., Ranwez, V., Vacherie, B., et al. (2012). Sequencing of the smallest Apicomplexan genome from the human pathogen Babesia microti. 
Nucleic Acids Res. 40, 9102-9114. doi: 10.1093/nar/gks700

Cruz, C. E., Fogaca, A. C., Nakayasu, E. S., Angeli, C. B., Belmonte, R., Almeida, I. C., et al. (2010). Characterization of proteinases from the midgut of Rhipicephalus (Boophilus) microplus involved in the generation of antimicrobial peptides. Parasit. Vectors 3:63. doi: 10.1186/1756-3305-3-63

Dai, J., Narasimhan, S., Zhang, L., Liu, L., Wang, P., and Fikrig, E. (2010). Tick histamine release factor is critical for Ixodes scapularis engorgement and transmission of the lyme disease agent. PLoS Pathog. 6:e1001205. doi: 10.1371/journal.ppat.1001205

Dai, J., Wang, P., Adusumilli, S., Booth, C. J., Narasimhan, S., Anguita, J., et al. (2009). Antibodies against a tick protein, Salp15, protect mice from the Lyme disease agent. Cell Host Microbe 6, 482-492. doi: 10.1016/j.chom.2009.10.006

Das, S., Banerjee, G., Deponte, K., Marcantonio, N., Kantor, F. S., and Fikrig, E. (2001). Salp25D, an Ixodes scapularis antioxidant, is 1 of 14 immunodominant antigens in engorged tick salivary glands. J. Infect. Dis. 184, 1056-1064. doi: $10.1086 / 323351$

De La Fuente, J. (2012). Vaccines for vector control: exciting possibilities for the future. Vet. J. 194, 139-140. doi: 10.1016/j.tvjl.2012. 07.029

De La Fuente, J., Almazan, C., Blas-Machado, U., Naranjo, V., Mangold, A. J., Blouin, E. F., et al. (2006). The tick protective antigen, 4D8, is a conserved protein involved in modulation of tick blood ingestion and reproduction. Vaccine 24, 4082-4095. doi: 10.1016/j.vaccine.2006.02.046

De La Fuente, J., Blouin, E. F., Manzano-Roman, R., Naranjo, V., Almazan, C., Perez De La Lastra, J. M., et al. (2007a). Functional genomic studies of tick cells in response to infection with the cattle pathogen, Anaplasma marginale. Genomics 90, 712-722. doi: 10.1016/j.ygeno.2007.08.009

De La Fuente, J., Kocan, K. M., Almazan, C., and Blouin, E. F. (2007b). RNA interference for the study and genetic manipulation of ticks. Trends Parasitol. 23, 427-433. doi: 10.1016/j.pt.2007.07.002

De La Fuente, J., Blouin, E. F., Manzano-Roman, R., Naranjo, V., Almazan, C., Perez De La Lastra, J. M., et al. (2008). Differential expression of the tick protective antigen subolesin in Anaplasma marginale- and A. phagocytophiluminfected host cells. Ann. N. Y. Acad. Sci. 1149, 27-35. doi: 10.1196/annals. 1428.056

De La Fuente, J., Moreno-Cid, J. A., Canales, M., Villar, M., De La Lastra, J. M., Kocan, K. M., et al. (2011). Targeting arthropod subolesin/akirin for the development of a universal vaccine for control of vector infestations and pathogen transmission. Vet. Parasitol. 181, 17-22. doi: 10.1016/j.vetpar.2011.04.018

De Silva, A. M., and Fikrig, E. (1995). Growth and migration of Borrelia burgdorferi in Ixodes ticks during blood feeding. Am. J. Trop. Med. Hyg. 53, 397-404.

De Silva, A. M., Telford, S. R. 3rd., Brunet, L. R., Barthold, S. W., and Fikrig, E. (1996). Borrelia burgdorferi OspA is an arthropod-specific transmission-blocking Lyme disease vaccine. J. Exp. Med. 183, 271-275. doi: 10.1084/jem.183.1.271

De Taeye, S. W., Kreuk, L., Van Dam, A. P., Hovius, J. W., and Schuijt, T. J. (2013). Complement evasion by Borrelia burgdorferi: it takes three to tango. Trends Parasitol. 29, 119-128. doi: 10.1016/j.pt.2012.12.001

Dumler, J. S., Barbet, A. F., Bekker, C. P., Dasch, G. A., Palmer, G. H., Ray, S. C., et al. (2001). Reorganization of genera in the families Rickettsiaceae and Anaplasmataceae in the order Rickettsiales: unification of some species of Ehrlichia with Anaplasma, Cowdria with Ehrlichia and Ehrlichia with Neorickettsia, descriptions of six new species combinations and designation of Ehrlichia equi and 'HGE agent' as subjective synonyms of Ehrlichia phagocytophila. Int. J. Syst. Evol. Microbiol. 51, 2145-2165. doi: 10.1099/00207713-51-6-2145

Dunham-Ems, S. M., Caimano, M. J., Pal, U., Wolgemuth, C. W., Eggers, C. H., Balic, A., et al. (2009). Live imaging reveals a biphasic mode of dissemination of Borrelia burgdorferi within ticks. J. Clin. Invest. 119, 3652-3665. doi: 10.1172/ JCI39401

Eggenberger, L. R., Lamoreaux, W. J., and Coons, L. B. (1990). Hemocytic encapsulation of implants in the tick Dermacentor variabilis. Exp. Appl. Acarol. 9, 279-287. doi: 10.1007/BF01193434

Ferrandon, D., Imler, J. L., Hetru, C., and Hoffmann, J. A. (2007). The Drosophila systemic immune response: sensing and signalling during bacterial and fungal infections. Nat. Rev. Immunol. 7, 862-874. doi: 10.1038/nri2194
Florin-Christensen, M., and Schnittger, L. (2009). Piroplasmids and ticks: a long-lasting intimate relationship. Front. Biosci. 14, 3064-3073. doi: $10.2741 / 3435$

Fogaca, A. C., Almeida, I. C., Eberlin, M. N., Tanaka, A. S., Bulet, P., and Daffre, S. (2006). Ixodidin, a novel antimicrobial peptide from the hemocytes of the cattle tick Boophilus microplus with inhibitory activity against serine proteinases. Peptides 27, 667-674 doi: 10.1016/j.peptides.2005.07.013

Fogaca, A. C., Da Silva, P. I. Jr., Miranda, M. T., Bianchi, A. G., Miranda, A., Ribolla, P. E., et al. (1999). Antimicrobial activity of a bovine hemoglobin fragment in the tick Boophilus microplus. J. Biol. Chem. 274, 25330-25334. doi: 10.1074/jbc.274.36.25330

Fogaca, A. C., Lorenzini, D. M., Kaku, L. M., Esteves, E., Bulet, P., and Daffre, S. (2004). Cysteine-rich antimicrobial peptides of the cattle tick Boophilus microplus: isolation, structural characterization and tissue expression profile. Dev. Comp. Immunol. 28, 191-200. doi: 10.1016/j.dci.2003.08.001

Francischetti, I. M., Sa-Nunes, A., Mans, B. J., Santos, I. M., and Ribeiro, J. M. (2009). The role of saliva in tick feeding. Front. Biosci. 14, 2051-2088. doi: 10.2741/3363

Galindo, R. C., Doncel-Perez, E., Zivkovic, Z., Naranjo, V., Gortazar, C., Mangold, A. J., et al. (2009). Tick subolesin is an ortholog of the akirins described in insects and vertebrates. Dev. Comp. Immunol. 33, 612-617. doi 10.1016/j.dci.2008.11.002

Garcia, S., Billecocq, A., Crance, J. M., Prins, M., Garin, D., and Bouloy, M. (2006). Viral suppressors of RNA interference impair RNA silencing induced by a Semliki Forest virus replicon in tick cells. J. Gen. Virol. 87, 1985-1989. doi: 10.1099/vir.0.81827-0

Gokudan, S., Muta, T., Tsuda, R., Koori, K., Kawahara, T., Seki, N., et al. (1999). Horseshoe crab acetyl group-recognizing lectins involved in innate immunity are structurally related to fibrinogen. Proc. Natl. Acad. Sci. U.S.A. 96, 10086-10091. doi: 10.1073/ pnas. 96.18 .10086

Grubhoffer, L., Rego, R. O. M., Hajdušek, O., Hypša, V., Kováø, V., Rudenko, N., et al. (2008). "Tick lectins and fibrinogenrelated proteins," in Ticks: Biology, Disease and Control, eds A. S. Bowman and P. A. Nuttall (Cambridge; New York: Cambridge
University Press), 127-142. doi: 10.1017/СВО9780511551802.007

Grunclova, L., Fouquier, H., Hypsa, V., and Kopacek, P. (2003). Lysozyme from the gut of the soft tick Ornithodoros moubata: the sequence, phylogeny and post-feeding regulation. Dev. Comp. Immunol. 27, 651-660. doi: 10.1016/S0145-305X(03)00052-1

Hanington, P. C., and Zhang, S. M. (2011). The primary role of fibrinogen-related proteins in invertebrates is defense, not coagulation. J. Innate. Immun. 3, 17-27. doi: $10.1159 / 000321882$

Heekin, A. M., Guerrero, F. D., Bendele, K. G., Saldivar, L., Scoles, G. A., Gondro, C., et al. (2012). Analysis of Babesia bovis infection-induced gene expression changes in larvae from the cattle tick, Rhipicephalus (Boophilus) microplus. Parasit. Vectors 5, 162. doi: 10.1186/1756-3305-5-162

Hillyer, J. F. (2010). Mosquito immunity. Adv. Exp. Med. Biol. 708, 218-238. doi: 10.1007/978-1-44198059-5_12

Hojgaard, A., Eisen, R. J., and Piesman, J. (2008). Transmission dynamics of Borrelia burgdorferi s.s. during the key third day of feeding by nymphal Ixodes scapularis (Acari: Ixodidae). J. Med. Entomol. 45, 732-736. doi: 10.1603/0022-2585 (2008)45[732:TDOBBS]2.0.CO;2

Horn, M., Nussbaumerova, M., Sanda, M., Kovarova, Z., Srba, J., Franta, Z., et al. (2009). Hemoglobin digestion in blood-feeding ticks: mapping a multipeptidase pathway by functional proteomics. Chem. Biol. 16, 1053-1063. doi: 10.1016/j.chembiol.2009.09.009

Hynes, W. L., Ceraul, S. M., Todd, S. M., Seguin, K. C., and Sonenshine, D. E. (2005). A defensin-like gene expressed in the black-legged tick Ixodes scapularis. Med. Vet. Entomol. 19, 339-344. doi: 10.1111/j.13652915.2005.00579.x

Hynes, W. L., Stokes, M. M., Hensley, S. M., Todd, S. M., and Sonenshine, D. E. (2008). Using RNA interference to determine the role of varisin in the innate immune system of the hard tick Dermacentor variabilis (Acari: Ixodidae). Exp. Appl. Acarol. 46, 7-15. doi: 10.1007/s10493-0089158-6

Inoue, N., Hanada, K., Tsuji, N., Igarashi, I., Nagasawa, H., Mikami, T., et al. (2001). Characterization of phagocytic hemocytes in Ornithodoros moubata (Acari: Ixodidae). J. Med. Entomol. 38, 514-519. doi: 10.1603/0022-2585-38.4.514 
Iwanaga, S., and Lee, B. L. (2005). Recent advances in the innate immunity of invertebrate animals. J. Biochem. Mol. Biol. 38, 128-150. doi: 10.5483/BMBRep.2005.38.2.128

Jaworski, D. C., Zou, Z., Bowen, C. J., Wasala, N. B., Madden, R., Wang, Y., et al. (2010). Pyrosequencing and characterization of immune response genes from the American dog tick, Dermacentor variabilis (L.). Insect Mol. Biol. 19, 617-630. doi: 10.1111/j.1365-2583.2010.01037.x

Johns, R., Ohnishi, J., Broadwater, A., Sonenshine, D. E., De Silva, A. M., and Hynes, W. L. (2001a). Contrasts in tick innate immune responses to Borrelia burgdorferi challenge: immunotolerance in Ixodes scapularis versus immunocompetence in Dermacentor variabilis (Acari: Ixodidae). J. Med. Entomol. 38, 99-107. doi: 10.1603/0022-2585-38.1.99

Johns, R., Sonenshine, D. E., and Hynes, W. L. (2001b). Identification of a defensin from the hemolymph of the American dog tick, Dermacentor variabilis. Insect Biochem. Mol. Biol. 31, 857-865. doi: 10.1016/S0965-1748(01)00031-5

Johns, R., Sonenshine, D. E., and Hynes, W. L. (2000). Response of the tick Dermacentor variabilis (Acari: Ixodidae) to hemocoelic inoculation of Borrelia burgdorferi (Spirochetales). J. Med. Entomol. 37, 265-270. doi: 10.1603/0022-258537.2.265

Jongejan, F., and Uilenberg, G. (2004). The global importance of ticks. Parasitology 129(Suppl.) S3-S14. doi: $10.1017 / S 0031182004005967$

Karim, S., Singh, P., and Ribeiro, J. M. (2011). A deep insight into the sialotranscriptome of the gulf coast tick, Amblyomma maculatum. PLoS ONE 6:e28525. doi: 10.1371/journal.pone. 0028525

Kaufman, W. R., and Phillips, J. E. (1973). Ion and Water-Balance in Ixodid Tick Dermacentor andersoni.1. Routes of Ion and Water Excretion. J. Exp. Biol. 58, 523-536.

Kawabata, S. (2010). Immunocompetent molecules and their response network in horseshoe crabs. Adv. Exp. Med. Biol. 708, 122-136. doi: 10.1007/978-1-4419-8059-5_7

Kawabata, S., and Tsuda, R. (2002). Molecular basis of non-self recognition by the horseshoe crab tachylectins. Biochim. Biophys. Acta 1572, 414-421. doi: 10.1016/S0304-4165(02)00322-7
Kocan, K. M., De La Fuente, J., and Blouin, E. F. (2008a). Advances toward understanding the molecular biology of the Anaplasmatick interface. Front. Biosci. 13, 7032-7045. doi: 10.2741/3208

Kocan, K. M., De La Fuente, J., Manzano-Roman, R., Naranjo, V., Hynes, W. L., and Sonenshine, D. E. (2008b). Silencing expression of the defensin, varisin, in male Dermacentor variabilis by RNA interference results in reduced Anaplasma marginale infections. Exp. Appl. Acarol. 46, 17-28. doi: 10.1007/s10493-008-9159-5

Kocan, K. M., De La Fuente, J., Blouin, E. F., Coetzee, J. F., and Ewing, S. A. (2010). The natural history of Anaplasma marginale. Vet. Parasitol. 167, 95-107. doi: 10.1016/j.vetpar.2009.09.012

Kocan, K. M., Goff, W. L., Stiller, D., Claypool, P. L., Edwards, W., Ewing, S. A., et al. (1992a). Persistence of Anaplasma marginale (Rickettsiales: Anaplasmataceae) in male Dermacentor andersoni (Acari: Ixodidae) transferred successively from infected to susceptible calves. J. Med. Entomol. 29, 657-668.

Kocan, K. M., Stiller, D., Goff, W. L., Claypool, P. L., Edwards, W., Ewing, S. A., et al. (1992b). Development of Anaplasma marginale in male Dermacentor andersoni transferred from parasitemic to susceptible cattle. Am. J. Vet. Res. 53, 499-507.

Kocan, K. M., Holbert, D., Edwards, W., Ewing, S. A., Barron, S. J., and Hair, J. A. (1986). Longevity of colonies of Anaplasma marginale in midgut epithelial cells of Dermacentor andersoni. Am. J. Vet. Res. 47, 1657-1661.

Kocan, K. M., Zivkovic, Z., Blouin, E. F., Naranjo, V., Almazan, C., Mitra, R., et al. (2009). Silencing of genes involved in Anaplasma marginale-tick interactions affects the pathogen developmental cycle in Dermacentor variabilis. BMC Dev. Biol. 9:42. doi: 10.1186/1471-213X9-42

Kopacek, P., Hajdusek, O., and Buresova, V. (2012). Tick as a model for the study of a primitive complement system. $A d v$. Exp. Med. Biol. 710, 83-93. doi: 10.1007/978-1-4419-5638-5_9

Kopacek, P., Hajdusek, O., Buresova, V., and Daffre, S. (2010). Tick innate immunity. Adv. Exp. Med. Biol. 708, 137-162. doi: 10.1007/978-1-44198059-5_8

Kopacek, P., Vogt, R., Jindrak, L., Weise, C., and Safarik, I. (1999). Purification and characterization of the lysozyme from the gut of the soft tick Ornithodoros moubata. Insect Biochem. Mol. Biol. 29, 989-997. doi: 10.1016/S09651748(99)00075-2

Kopacek, P., Weise, C., Saravanan, T., Vitova, K., and Grubhoffer, L. (2000). Characterization of an alpha-macroglobulin-like glycoprotein isolated from the plasma of the soft tick Ornithodoros moubata. Eur. J. Biochem. 267, 465-475. doi 10.1046/j.1432-1327.2000.01020.x

Kovar, V., Kopacek, P., and Grubhoffer, L. (2000). Isolation and characterization of Dorin, M, a lectin from plasma of the soft tick Ornithodoros moubata. Insect Biochem. Mol. Biol. 30, 195-205. doi: 10.1016/S09651748(99)00107-1

Krober, T., and Guerin, P. M. (2007) In vitro feeding assays for hard ticks. Trends Parasitol. 23, 445-449. doi: 10.1016/j.pt.2007.07.010

Kumar, S., Molina-Cruz, A., Gupta, L., Rodrigues, J., and Barillas-Mury, C. (2010). A peroxidase/dual oxidase system modulates midgut epithelial immunity in Anopheles gambiae. Science 327, 1644-1648. doi: 10.1126/science. 1184008

Kurscheid, S., Lew-Tabor, A. E., Rodriguez Valle, M., Bruyeres, A G., Doogan, V. J., Munderloh, U. G., et al. (2009). Evidence of a tick RNAi pathway by comparative genomics and reverse genetics screen of targets with known loss-of-function phenotypes in Drosophila. BMC Mol. Biol. 10:26. doi: 10.1186/1471-2199-10-26

Lai, R., Takeuchi, H., Lomas, L. O. Jonczy, J., Rigden, D. J., Rees, H. H., et al. (2004). A new type of antimicrobial protein with multiple histidines from the hard tick, Amblyomma hebraeum. FASEB J. 18, 1447-1449.

Lara, F. A., Lins, U., Bechara, G. H., and Oliveira, P. L. (2005). Tracing heme in a living cell: hemoglobin degradation and heme traffic in digest cells of the cattle tick Boophilus microplus. J. Exp. Biol. 208, 3093-3101. doi: 10.1242/jeb.01749

Lara, F. A., Lins, U., Paiva-Silva, G., Almeida, I. C., Braga, C. M., Miguens, F. C., et al. (2003). A new intracellular pathway of haem detoxification in the midgut of the cattle tick Boophilus microplus: aggregation inside a specialized organelle, the hemosome. J. Exp. Biol. 206, 1707-1715. doi: 10.1242/jeb.00334

Lehane, M. J., Aksoy, S., and Levashina, E. (2004). Immune responses and parasite transmission in blood-feeding insects. Trends
Parasitol. 20, 433-439. doi: 10.1016/j.pt.2004.07.002

Lindbo, J. A., Silva-Rosales, L., Proebsting, W. M., and Dougherty, W. G. (1993). Induction of a highly specific antiviral state in transgenic plants: implications for regulation of gene expression and virus resistance. Plant Cell 5, 1749-1759.

Liu, L., Dai, J., Zhao, Y. O., Narasimhan, S., Yang, Y., Zhang, L., et al. (2012). Ixodes scapularis JAK-STAT pathway regulates tick antimicrobial peptides, thereby controlling the agent of human granulocytic anaplasmosis. J. Infect. Dis. 206, 1233-1241. doi: 10.1093/infdis/jis484

Liu, L., Narasimhan, S., Dai, J., Zhang, L., Cheng, G., and Fikrig, E. (2011). Ixodes scapularis salivary gland protein P11 facilitates migration of Anaplasma phagocytophilum from the tick gut to salivary glands. EMBO Rep. 12, 1196-1203. doi: 10.1038/embor.2011.177

Liu, Z., Liu, H., Liu, X., and Wu, X. (2008). Purification and cloning of a novel antimicrobial peptide from salivary glands of the hard tick, Ixodes sinensis. Comp. Biochem. Physiol. B Biochem. Mol. Biol. 149, 557-561. doi: 10.1016/j.cbpb.2007.10.002

Loosova, G., Jindrak, L., and Kopacek, P. (2001). Mortality caused by experimental infection with the yeast Candida haemulonii in the adults of Ornithodoros moubata (Acarina: Argasidae). Folia Parasitol. 48, 149-153.

Lu, X., Che, Q., Lv, Y., Wang, M., Lu, Z., Feng, F., et al. (2010). A novel defensin-like peptide from salivary glands of the hard tick, Haemaphysalis longicornis. Protein Sci. 19, 392-397.

Mans, B. J. (2011). Evolution of vertebrate hemostatic and inflammatory control mechanisms in blood-feeding arthropods. J. Innate. Immun. 3, 41-51. doi: $10.1159 / 000321599$

Mans, B. J., Andersen, J. F., Francischetti, I. M., Valenzuela, J. G., Schwan, T. G., Pham, V. M., et al. (2008). Comparative sialomics between hard and soft ticks: implications for the evolution of blood-feeding behavior. Insect Biochem. Mol. Biol. 38, 42-58. doi: 10.1016/j.ibmb.2007.09.003

Megy, K., Emrich, S. J., Lawson, D., Campbell, D., Dialynas, E., Hughes, D. S., et al. (2012). VectorBase: improvements to a bioinformatics resource for invertebrate vector genomics. Nucleic Acids Res. 40, D729-D734. doi: 10.1093/nar/gkr1089 
Merino, O., Almazan, C., Canales, M., Villar, M., Moreno-Cid, J. A., Galindo, R. C., et al. (2011). Targeting the tick protective antigen subolesin reduces vector infestations and pathogen infection by Anaplasma marginale and Babesia bigemina. Vaccine 29, 8575-8579. doi: 10.1016/j.vaccine.2011.09.023

Myers, J. W., and Ferrell, J. E. (2005). Silencing gene expression with Dicer-generated siRNA pools. Methods Mol. Biol. 309, 93-196.

Nakajima, Y., Ogihara, K., Taylor, D., and Yamakawa, M. (2003). Antibacterial hemoglobin fragments from the midgut of the soft tick, Ornithodoros moubata (Acari: Argasidae). J. Med. Entomol. 40, 78-81. doi: 10.1603/0022-2585-40.1.78

Nakajima, Y., Van Der Goes Van NatersYasui, A., Taylor, D., and Yamakawa, M. (2001). Two isoforms of a member of the arthropod defensin family from the soft tick, Ornithodoros moubata (Acari: Argasidae). Insect Biochem. Mol. Biol. 31, 747-751. doi: 10.1016/S0965-1748 (01)00066-2

Nakajima, Y., Van Der Goes Van Naters-Yasui, A., Taylor, D., and Yamakawa, M. (2002). Antibacterial peptide defensin is involved in midgut immunity of the soft tick, Ornithodoros moubata. Insect Mol. Biol. 11, 611-618. doi: 10.1046/j.1365-2583.2002.00372.x

Naranjo, N., Ayllón, N., Pérez De La Lastra, J. M., Galindo, R. C., Kocan, K. M., Blouin, E. F., et al. (2013). Reciprocal regulation of NF-kB (Relish) and Subolesin in the tick vector, Ixodes scapularis. PLoS ONE. 8:e65915. doi: 10.1371/journal.pone. 0065915

Narasimhan, S., Deponte, K., Marcantonio, N., Liang, X., Royce, T. E., Nelson, K. F., et al. (2007a). Immunity against Ixodes scapularis salivary proteins expressed within 24 hours of attachment thwarts tick feeding and impairs Borrelia transmission. PLoS ONE 2:e451. doi: 10.1371/journal.pone.0000451

Narasimhan, S., Sukumaran, B., Bozdogan, U., Thomas, V., Liang, X., Deponte, K., et al. (2007b). A tick antioxidant facilitates the Lyme disease agent's successful migration from the mammalian host to the arthropod vector. Cell Host Microbe 2, 7-18. doi: 10.1016/j.chom.2007.06.001

Nelson, N. (2003). A journey from mammals to yeast with vacuolar H+-ATPase (V-ATPase). J. Bioenerg. Biomembr. 35, 281-289. doi: 10.1023/A:1025768529677
Ng, P. M., Le Saux, A., Lee, C. M., Tan, N. S., Lu, J., Thiel, S., et al. (2007). C-reactive protein collaborates with plasma lectins to boost immune response against bacteria. $E M B O$ J. 26, 3431-3440. doi: 10.1038/sj.emboj.7601762

Nonaka, M., and Kimura, A. (2006). Genomic view of the evolution of the complement system. Immunogenetics 58, 701-713. doi: 10.1007/s00251-006-0142-1

Oakley, A. (2011). Glutathione transferases: a structural perspective. Drug Metab. Rev. 43, 138-151. doi: 10.3109/03602532.2011.558093

Ohnishi, J., Piesman, J., and De Silva, A. M. (2001). Antigenic and genetic heterogeneity of Borrelia burgdorferi populations transmitted by ticks. Proc. Natl. Acad. Sci. U.S.A. 98, 670-675. doi: 10.1073/pnas.98.2.670

Okubo, K., Yokoyama, N., Govind, Y., Alhassan, A., and Igarashi, I. (2007). Babesia bovis: effects of cysteine protease inhibitors on in vitro growth. Exp. Parasitol. 117, 214-217. doi: 10.1016/j.exppara.2007.04.009

Oliveira, J. H., Goncalves, R. L., Lara, F. A., Dias, F. A., Gandara, A. C., Menna-Barreto, R. F., et al. (2011). Blood meal-derived heme decreases ROS levels in the midgut of Aedes aegypti and allows proliferation of intestinal microbiota. PLoS Pathog. 7:e1001320. doi: 10.1371/journal.ppat.1001320

Oliveira Gde, A., Lieberman, J., and Barillas-Mury, C. (2012). Epithelial nitration by a peroxidase/NOX5 system mediates mosquito antiplasmodial immunity. Science 335, 856-859. doi: 10.1126/science. 1209678

Osta, M. A., Christophides, G. K., Vlachou, D., and Kafatos, F. C. (2004). Innate immunity in the malaria vector Anopheles gambiae: comparative and functional genomics. J. Exp. Biol. 207, 2551-2563. doi: 10.1242/jeb.01066

Pagel Van Zee, J., Geraci, N. S., Guerrero, F. D., Wikel, S. K., Stuart, J. J., Nene, V. M., et al. (2007). Tick genomics: the Ixodes genome project and beyond. Int J. Parasitol. 37, 1297-1305. doi: 10.1016/j.ijpara.2007.05.011

Pal, U., Li, X., Wang, T., Montgomery, R. R., Ramamoorthi, N., Desilva, A. M., et al. (2004). TROSPA, an Ixodes scapularis receptor for Borrelia burgdorferi. Cell 119, 457-468. doi: 10.1016/j.cell.2004.10.027

Pedra, J. H., Narasimhan, S., Rendic, D., Deponte, K., Bell-Sakyi, L., Wilson, I. B., et al. (2010). Fucosylation enhances colonization of ticks by
Anaplasma phagocytophilum. Cell. Microbiol. 12, 1222-1234. doi: 10.1111/j.1462-5822.2010.01464.x

Pereira, L. S., Oliveira, P. L., BarjaFidalgo, C., and Daffre, S. (2001). Production of reactive oxygen species by hemocytes from the cattle tick Boophilus microplus. Exp. Parasitol. 99, 66-72. doi: 10.1006/expr.2001.4657

Pichu, S., Ribeiro, J. M., and Mather, T. N. (2009). Purification and characterization of a novel salivary antimicrobial peptide from the tick, Ixodes scapularis. Biochem. Biophys. Res. Commun. 390, 511-515. doi: 10.1016/j.bbrc.2009.09.127

Rachinsky, A., Guerrero, F. D., and Scoles, G. A. (2007). Differential protein expression in ovaries of uninfected and Babesia-infected southern cattle ticks, Rhipicephalus (Boophilus) microplus. Insect Biochem. Mol. Biol. 37, 1291-1308. doi: 10.1016/j.ibmb.2007.08.001

Rachinsky, A., Guerrero, F. D., and Scoles, G. A. (2008). Proteomic profiling of Rhipicephalus (Boophilus) microplus midgut responses to infection with Babesia bovis. Vet. Parasitol. 152, 294-313. doi: 10.1016/j.vetpar.2007.12.027

Radolf, J. D., and Samuels, D. S. (2010). Borrelia: molecular biology, host interaction, and pathogenesis. Norfolk, VA: Caister Academic Press.

Ramamoorthi, N., Narasimhan, S., Pal, U., Bao, F. K., Yang, X. F. F., Fish, D., et al. (2005). The Lyme disease agent exploits a tick protein to infect the mammalian host. Nature 436, 573-577. doi: 10.1038/nature03812

Ratcliff, F. G., Macfarlane, S. A., and Baulcombe, D. C. (1999). Gene silencing without DNA. rnamediated cross-protection between viruses. Plant Cell 11, 1207-1216.

Reeves, M. A., and Hoffmann, P. R. (2009). The human selenoproteome: recent insights into functions and regulation. Cell. Mol. Life Sci. 66, 2457-2478. doi: 10.1007/s00018-009-0032-4

Rego, R. O., Hajdusek, O., Kovar, V., Kopacek, P., Grubhoffer, L., and Hypsa, V. (2005). Molecular cloning and comparative analysis of fibrinogen-related proteins from the soft tick Ornithodoro moubata and the hard tick Ixodes ricinus. Insect Biochem. Mol. Biol. 35, 991-1004. doi: 10.1016/j.ibmb. 2005.04.001

Rego, R. O., Kovar, V., Kopacek, P., Weise, C., Man, P., Sauman, I., et al. (2006). The tick plasma lectin, Dorin, $M$, is a fibrinogenrelated molecule. Insect Biochem.
Mol. Biol. 36, 291-299. doi: 10.1016/j.ibmb.2006.01.008

Ribeiro, J. M., Alarcon-Chaidez, F., Francischetti, I. M., Mans, B. J., Mather, T. N., Valenzuela, J. G., et al. (2006). An annotated catalog of salivary gland transcripts from Ixodes scapularis ticks. Insect Biochem. Mol. Biol. 36, 111-129. doi: 10.1016/j.ibmb.2005.11.005

Rittig, M. G., Kuhn, K. H., Dechant, C. A., Gauckler, A., Modolell, M., Ricciardi-Castagnoli, P., et al. (1996). Phagocytes from both vertebrate and invertebrate species use "coiling" phagocytosis. Dev. Comp. Immunol. 20, 393-406. doi: 10.1016/S0145-305X(96)00023-7

Rollend, L., Fish, D., and Childs, J. E. (2013). Transovarial transmission of Borrelia spirochetes by Ixodes scapularis: a summary of the literature and recent observations. Ticks Tick Borne Dis. 4, 46-51. doi: 10.1016/j.ttbdis.2012.06.008

Rudenko, N., Golovchenko, M., Edwards, M. J., and Grubhoffer, L. (2005). Differential expression of Ixodes ricinus tick genes induced by blood feeding or Borrelia burgdorferi infection. J. Med. Entomol. 42, 36-41. doi: 10.1603/0022-2585 (2005)042 [0036:DEOIRT]2.0.CO;2

Saravanan, T., Weise, C., Sojka, D., and Kopacek, P. (2003). Molecular cloning, structure and bait region splice variants of alpha2-macroglobulin from the soft tick Ornithodoros moubata. Insect Biochem. Mol. Biol. 33, 841-851. doi: 10.1016/S0965-1748(03)00083-3

Severo, M. S., Sakhon, O. S., Choy, A., Stephens, K. D., and Pedra, J. H. (2013). The 'ubiquitous' reality of vector immunology. Cell Microbiol. 15, 1070-1078. doi: $10.1111 / \mathrm{cmi} .12128$

Schuijt, T. J., Coumou, J., Narasimhan, S., Dai, J., Deponte, K., Wouters, D., et al. (2011a). A tick mannosebinding lectin inhibitor interferes with the vertebrate complement cascade to enhance transmission of the lyme disease agent. Cell Host Microbe 10, 136-146. doi: 10.1016/j.chom.2011.06.010

Schuijt, T. J., Narasimhan, S., Daffre, S., Deponte, K., Hovius, J. W., Van't Veer, C., et al. (2011b). Identification and characterization of Ixodes scapularis antigens that elicit tick immunity using yeast surface display. PLoS ONE 6:e15926. doi: 10.1371/journal.pone.0015926

Schwan, T. G., Piesman, J., Golde, W. T., Dolan, M. C., and Rosa, P. A. (1995). Induction of an outer surface protein on Borrelia 
burgdorferi during tick feeding. Proc. Natl. Acad. Sci. U.S.A. 92, 2909-2913. doi: 10.1073/ pnas.92.7.2909

Shkap, V., Kocan, K., Molad, T., Mazuz, M., Leibovich, B., Krigel, Y., et al. (2009). Experimental transmission of field Anaplasma marginale and the $A$. centrale vaccine strain by Hyalomma excavatum, Rhipicephalus sanguineus and Rhipicephalus (Boophilus) annulatus ticks. Vet. Microbiol. 134, 254-260. doi: 10.1016/j.vetmic.2008.08.004

Silva, F. D., Rezende, C. A., Rossi, D. C., Esteves, E., Dyszy, F. H., Schreier, S., et al. (2009). Structure and mode of action of microplusin, a copper II-chelating antimicrobial peptide from the cattle tick Rhipicephalus (Boophilus) microplus. J. Biol. Chem. 284, 34735-34746. doi: 10.1074/jbc.M109.016410

Söderhäll, K. (2010). Invertebrate Immunity. New York, NY, Austin, Tex.: Springer Science+Business Media; Landes Bioscience. doi: 10.1007/978-1-4419-8059-5

Sojka, D., Franta, Z., Horn, M., Caffer, C. R., Mareš, M., and Kopáèek, P. (2013). New insights into the machinery of blood digestion in ticks. Trends Parasitol. 29, 276-285. doi: 10.1016/j.pt.2013.04.002

Sojka, D., Franta, Z., Horn, M., Hajdusek, O., Caffrey, C. R., Mares, M., et al. (2008). Profiling of proteolytic enzymes in the gut of the tick Ixodes ricinus reveals an evolutionarily conserved network of aspartic and cysteine peptidases. Parasit. Vectors 1, 7. doi: 10.1186/1756-3305-1-7

Sonenshine, D. E. (1991). Biology of Ticks. New York, NY: Oxford University Press.

Sonenshine, D. E., and Hynes, W. L. (2008). Molecular characterization and related aspects of the innate immune response in ticks. Front. Biosci. 13, 7046-7063. doi: 10.2741/3209

Sonenshine, D. E., Hynes, W. L., Ceraul, S. M., Mitchell, R., and Benzine, T. (2005). Host blood proteins and peptides in the midgut of the tick Dermacentor variabilis contribute to bacterial control. Exp. Appl. Acarol. 36, 207-223. doi: 10.1007/s10493005-2564-0

Stanek, G., Wormser, G. P., Gray, J., and Strle, F. (2012). Lyme borreliosis. Lancet 379, 461-473. doi: 10.1016/S0140-6736(11)60103-7
Steere, A. C., Coburn, J., and Glickstein, L. (2004). The emergence of Lyme disease. J. Clin. Invest. 113, 1093-1101.

Sterba, J., Dupejova, J., Fiser, M., Vancova, M., and Grubhoffer, L. (2011). Fibrinogen-related proteins in ixodid ticks. Parasit. Vectors 4 127. doi: 10.1186/1756-3305-4-127

Sukumaran, B., Narasimhan, S., Anderson, J. F., Deponte, K., Marcantonio, N., Krishnan, M. N., et al. (2006). An Ixodes scapularis protein required for survival of Anaplasma phagocytophilum in tick salivary glands. J. Exp. Med. 203, 1507-1517. doi: 10.1084/jem.20060208

Sultana, H., Neelakanta, G., Kantor, F. S., Malawista, S. E., Fish, D., Montgomery, R. R., et al. (2010). Anaplasma phagocytophilum induces actin phosphorylation to selectively regulate gene transcription in Ixodes scapularis ticks. J. Exp. Med. 207, 1727-1743. doi: 10.1084/jem.20100276

Tsuji, N., Battsetseg, B., Boldbaatar, D., Miyoshi, T., Xuan, X., Oliver, J. H., et al. (2007). Babesial vector tick defensin against Babesia sp. parasites. Infect. Immun. 75, 3633-3640. doi: 10.1128/IAI. 00256-07

Tsuji, N., and Fujisaki, K. (2007). Longicin plays a crucial role in inhibiting the transmission of Babesia parasites in the vector tick Haemaphysalis longicornis. Future Microbiol. 2, 575-578. doi: 10.2217/17460913.2.6.575

Tsuji, N., Miyoshi, T., Battsetseg, B., Matsuo, T., Xuan, X., and Fujisaki, K. (2008). A cysteine protease is critical for Babesia spp. transmission in Haemaphysalis ticks. PLoS Pathog. 4:e1000062. doi: 10.1371/journal.ppat.1000062

Tyson, K., Elkins, C., Patterson, H., Fikrig, E., and De Silva, A. (2007). Biochemical and functional characterization of Salp20, an Ixodes scapularis tick salivary protein that inhibits the complement pathway. Insect Mol. Biol. 16, 469-479. doi: 10.1111/j.1365-2583. 2007.00742.x

Tyson, K. R., Elkins, C., and De Silva, A. M. (2008). A novel mechanism of complement inhibition unmasked by a tick salivary protein that binds to properdin. J. Immunol. 180, 3964-3968.

Urieli-Shoval, S., Linke, R. P., and Matzner, Y. (2000). Expression and function of serum amyloid A, a major acute-phase protein, in normal and disease states. Curr. Opin. Hematol. 7, 64-69. doi: 10.1097/00062752-20000100000012

Villar, M., Ayllon, N., Busby, A. T., Galindo, R. C., Blouin, E. F., Kocan, K. M., et al. (2010a). Expression of heat shock and other stress response proteins in ticks and cultured tick cells in response to Anaplasma spp. infection and heat Shock. Int J. Proteomics 2010, 657261. doi: 10.1155/2010/657261

Villar, M., Torina, A., Nunez, Y., Zivkovic, Z., Marina, A., Alongi, A., et al. (2010b). Application of highly sensitive saturation labeling to the analysis of differential protein expression in infected ticks from limited samples. Proteome Sci. 8:43. doi: 10.1186/14775956-8-43

Wang, W. A., Groenendyk, J., and Michalak, M. (2012). Calreticulin signaling in health and disease. Int. J. Biochem. Cell Biol. 44, 842-846. doi: 10.1016/j.biocel.2012. 02.009

Wang, Y., and Zhu, S. (2011). The defensin gene family expansion in the tick Ixodes scapularis. Dev. Comp. Immunol. 35, 1128-1134. doi: 10.1016/j.dci.2011.03.030

Woldehiwet, Z. (2010). The natural history of Anaplasma phagocytophilum. Vet. Parasitol. 167, 108-122. doi: 10.1016/j.vetpar.2009.09.013

Yu, D., Sheng, Z., Xu, X., Li, J., Yang, H., Liu, Z., et al. (2006). A novel antimicrobial peptide from salivary glands of the hard tick, Ixodes sinensis. Peptides 27, 31-35. doi: 10.1016/j.peptides.2005. 06.020

Zhang, L., Zhang, Y., Adusumilli, S., Liu, L., Narasimhan, S., Dai, J., et al. (2011). Molecular interactions that enable movement of the Lyme disease agent from the tick gut into the hemolymph. PLoS Pathog. 7:e1002079. doi: 10.1371/journal.ppat.1002079

Zhou, J., Liao, M., Ueda, M., Gong, H., Xuan, X., and Fujisaki, K. (2007). Sequence characterization and expression patterns of two defensin-like antimicrobial peptides from the tick Haemaphysalis longicornis. Peptides 28, 1304-1310. doi: 10.1016/j.peptides. 2007.04.019

Zhou, J., Ueda, M., Umemiya, R., Battsetseg, B., Boldbaatar, D., Xuan,
X., et al. (2006). A secreted cystatin from the tick Haemaphysalis longicornis and its distinct expression patterns in relation to innate immunity. Insect Biochem. Mol. Biol. 36, 527-535. doi: 10.1016/j.ibmb. 2006.03.003

Zhu, Y., Thangamani, S., Ho, B., and Ding, J. L. (2005). The ancient origin of the complement system. EMBO J. 24, 382-394. doi: 10.1038/sj.emboj. 7600533

Zintl, A., Mulcahy, G., Skerrett, H. E., Taylor, S. M., and Gray, J. S. (2003). Babesia divergens, a bovine blood parasite of veterinary and zoonotic importance. Clin. Microbiol. Rev. 16, 622-636. doi: 10.1128/CMR.16.4. 622-636.2003

Zivkovic, Z., Blouin, E. F., ManzanoRoman, R., Almazan, C., Naranjo, V., Massung, R. F., et al. (2009). Anaplasma phagocytophilum and Anaplasma marginale elicit different gene expression responses in cultured tick cells. Comp. Funct. Genomics 705034. doi:10.1155/2009/705034

Zivkovic, Z., Torina, A., Mitra, R., Alongi, A., Scimeca, S., Kocan, K. M., et al. (2010). Subolesin expression in response to pathogen infection in ticks. BMC Immunol. 11:7. doi: 10.1186/14712172-11-7

Conflict of Interest Statement: The authors declare that the research was conducted in the absence of any commercial or financial relationships that could be construed as a potential conflict of interest.

Received: 24 May 2013; accepted: 13 June 2013; published online: 16 July 2013. Citation: Hajdušek O, Šima R, Ayllón $N$, Jalovecká $M$, Perner $J$, de la Fuente $J$ and Kopáček P (2013) Interaction of the tick immune system with transmitted pathogens. Front. Cell. Infect. Microbiol. 3:26. doi: 10.3389/fcimb.2013.00026

Copyright (c) 2013 Hajdušek, Šima, Ayllón, Jalovecká, Perner, de la Fuente and Kopáček. This is an open-access article distributed under the terms of the Creative Commons Attribution License, which permits use, distribution and reproduction in other forums, provided the original authors and source are credited and subject to any copyright notices concerning any third-party graphics etc. 